University of Rhode Island

DigitalCommons@URI

Open Access Dissertations

1997

\title{
Training Caregivers to Intervene in the Exploratory Play of Young Children with Developmental Delays
}

Susan L. Curley

University of Rhode Island

Follow this and additional works at: https://digitalcommons.uri.edu/oa_diss

\section{Recommended Citation}

Curley, Susan L., "Training Caregivers to Intervene in the Exploratory Play of Young Children with Developmental Delays" (1997). Open Access Dissertations. Paper 1025.

https://digitalcommons.uri.edu/oa_diss/1025

This Dissertation is brought to you for free and open access by DigitalCommons@URI. It has been accepted for inclusion in Open Access Dissertations by an authorized administrator of DigitalCommons@URI. For more information, please contact digitalcommons-group@uri.edu. 
TRAINING CAREGIVERS TO INTERVENE IN THE EXPLORATORY PLAY OF YOUNG CHILDREN WITH DEVELOPMENTAL DELAYS BY SUSAN L. CURLEY

A DISSERTATION SUBMITTED IN PARTIAL FULFILLMENT OF THE REQUIREMENTS FOR THE DEGREE OF DOCTOR OF PHILOSOPHY IN PSYCHOLOGY 
Play, particularly exploratory play, can be viewed as the arena in which a series of interactions between a child and the environment occur. However, children with developmental delays appear to be less able to fully engage in exploratory play and utilize the environmental information that such play provides (Krakow \& Kopp, 1983). There is also preliminary evidence that caregivers can be trained to use behaviors that facilitate exploratory play when engaged with their children (Belsky, Goode, \& Most, 1981). The purpose of the present study was to explore the potential of training caregivers to facilitate the exploratory play of developmentally delayed children using an experimental design. Additionally, relationships between caregiver and child exploratory play behavior are considered.

Using pre- and post intervention videotaped data of 29 mothers and their children, caregiver and child exploratory play was examined across two groups. Fifteen children and caregivers were assigned to a group that provided caregivers with specific training on strategies to enhance exploratory play. The remaining fourteen children and caregivers comprised a group that received general information on child development.

Results did not indicate any significant differences between these groups in maternal or child behavior, however significant differences in the quality of children's play were noted over time. Additionally changes in the patterns of relationships between maternal behavior and child exploratory behavior are noted over 
time. Current findings are discussed in the context of previous findings on exploratory play.

David Caruso 
Acknowledgments

Reflecting on the process of completing of my doctorate and this dissertation, which has occupied such a large part of my life over the past several years, has been enlightening. The conclusions that I draw are that, although I spent a number of solitary nights with my computer, it has been a team process. I'd like to thank the members of my team. This team has included the best coach a person could ask for, my major professor, David Caruso. Other key members of my team included committee members, Dr. Collyer and Dr. Kulberg. I'd also like to thank the staff and families of the early intervention centers that participated in the study. In particular, I'd like to thank Brenda Dzeidzic, who as the director of the Metropolitan Regional Early Intervention Center, not only allowed me to collect data but who also gave me a great job that deepened my dedication to the philosophy of early intervention. Additionally, I'm deeply indebted to my colleague, Lynne Andreozzi, who offered me moral support in addition to assistance with data analysis.

Finally no team is complete without its fans. I am grateful for all the encouragement and the occasional push my fans have given me. I'd like to thank my husband, Steve, for all of his many contributions to this project. I'd also like to thank my parents and my brothers, Eddie, Steve and Michael for all the support they have given me over these years. 
Acknowledgments

List of Tables

Introduction

Statement of Problem

Justification of the Study

1

Review of Relevant Literature

2

Research Questions

2

Method

Participants

12

Instrumentation

12

Developmental Assessment

13

Summary of Coding

13

Developmental Level Coding 14

Exploratory Quality Coding

16

Exploratory Quantity Coding 18

Caregiver Behavior Coding 19

Procedure

20

Sequence of Eight Week Intervention 21

Format of Intervention Sessions 23

Results

Demographic and Descriptive Data

Multivariate Analyses of Variance

Univariate Analyses of Variance

Relationship Between Child and

Caregiver Behavior

Parent Responses to Group

Participation

Discussion

The Effect Of Group Participation

On Caregiver Behavior And Child

Exploratory Play

Relationships Between Caregiver

and Child Exploratory Play Behaviors

Before and After the Intervention

Period

Exploratory Play Behavior In

Developmentally Delayed Children

42

Conclusion 
'Limitations and Recommendations

for Further Study

Tables

$\begin{array}{lll}\text { Table } & 1 & 15 \\ \text { Table } & 2 & 16 \\ \text { Table } & 3 & 19 \\ \text { Table } & 4 & 16 \\ \text { Table } & 5 & 25 \\ \text { Table } & 6 & 26 \\ \text { Table } & 7 & 28 \\ & & 29\end{array}$

Appendices

Appendix A

Demographic Questionnaire 49

Appendix B

Infant Behavior Coding Sheet 50

Appendix $\mathrm{C}$

Caregiver Behavior Coding

Sheet

Appendix D

Introductory Letter

Appendix E

Consent Form

54

Appendix $\mathrm{F}$

Standardized Instructions

Appendix G

Standardized Set of Toys $\quad 58$

Appendix $\mathrm{H}$

Overview of the Eight Weekly

Sessions for the Comparison Groups 59

Appendix I

Group Activity Plans $\quad 61$

Appendix $\mathrm{J}$

Parent Feedback Sheet 90

Appendix $\mathrm{K}$

Analysis of Variance for the Effect

of Time on Children's Behavior During

Independent Play

91

Appendix L

Analysis of Variance for the Effect of

Time on Children's Behavior During Play with

Caregiver

92 
Appendix $\mathrm{M}$

Graphs of the Means of Variables

Significantly Effected by the Factor Time 93

Bibliography

100 
List of Tables

1. Operational Definitions of Developmental Level Variables and Behaviors used to Derive Those Variable

2. Operational Definitions of Exploratory Behavior Used to Determined Quality and Quantity of Exploratory Play and Variables Derived From Those Behaviors

3. Operational Definitions of Caregiver Variables

4. Descriptive Information on Children

5. Pre and Post-Test Means and Standard Deviations for Caregiver Behavior by Treatment Group

6. Pre and Post-Test Means and Standard Deviations for Child Behavior during Independent Play by Treatment Group

7. Pre and Post-Test Means and Standard Deviations for Child Behavior during Play with Caregiver by Treatment Group 
TRAINING CAREGIVERS TO INTERVENE IN THE EXPLORATORY PLAY

OF YOUNG CHILDREN WITH DEVELOPMENTAL DELAYS

Statement of The Problem

In the past, play has been called a window into cognitive development. Play, particularly exploratory play, can be viewed as the arena in which a series of interactions between a child and the environment occur. Exploratory play, as defined by Caruso (1985), is behavior which generates or maximizes informational feedback from objects in the environment (Caruso, 1985). In exploratory play the focus is on initial interactions with relatively novel objects. These interactions provide a child with learning opportunities which contribute to cognitive growth (Belsky \& Most, 1980). The motivation to explore the environment through play is considered to be "an integral part of development for all children," (Hauser-Cram, 1996, p. 236).

However, children with developmental delays appear to be less able to fully engage in exploratory play and utilize the environmental information that such play provides (Krakow \& Kopp, 1983). Research has suggested that the actions of caregivers who play a primary role in their children's environment can facilitate the exploratory : play of typically - developing children (Anzalone, 1994). There is also preliminary evidence that caregivers can be trained to use facilitory behaviors when playing with their children (Belsky, Goode \& Most, 1981). The purpose of the present study is to explore the potential of training caregivers to facilitate the exploratory play of developmentally delayed children using an experimental design. It is hypothesized that such training teaches caregivers to structure 
child play appropriately, to be responsive to child cues, and to provide useful environmental feedback to children. Children were expected to gain exploratory play skills and use those skills more effectively.

\section{Justification For The Study}

The present study is designed to contribute to current understanding of exploratory play in a number of ways. First, the study uses an experimental design, rather than the non-experimental designs used primarily in the past, to test hypotheses regarding exploratory play and its relationship to caregiver behavior. Second, the study examines the relationship between several exploratory play variables used by various researchers in the past. Finally, the training used in the study may provide additional support for the widespread trend in early intervention programs to train parents to provide services to their children. It may also provide a model of training and training evaluation that early intervention centers can use for programming.

\section{Review Of Relevant Literature}

Play has long been recognized as an important human endeavor. For example, it is reported that Plato encouraged young boys to play with apples in the belief that the experience would later be beneficial in learning math concepts (Rubin, Fein, \& Vandenburg, 1983). Although there is general agreement that play is important, the reason for its importance has not always been agreed upon. Four primary theories have been advanced over the years to explain the 
importance of play. The eighteenth century philosopher, Schiller, ( as cited in Rubin, Fein, \& Vandenburg, 1983) proposed play as a means of releasing surplus energy. Larazus (as cited in Rubin, Fein, \& Vandenburg, 1983) hypothesized that play serves to relieve stress and promote relaxation. G. Stanley Hall stated that play was part of the recapitulation of evolution that all individuais undergo (as cited in Rubin, Fein, \& Vandenburg, 1983). Piaget (1952) proposed that play is a means of consolidating, or integrating, cognitive skills for current and future use.

The theories of Schiller, Larazus, and Hall may be of limited use in explaining actual observed play. For example, none of these theories can account for why tired children still play (Weisler \& McCall, 1976; Rubin, Fein, \& Vandenburg, 1983). Piaget's work, on the other hand, has provided a valuable framework for conceptualizing play. Piaget was the first to emphasize the importance of self-initiated exploratory play. The basis for Piaget's writings on play are formed within a theory of interactionism. Piaget's work is based on the belief that the coordination of mind and body is achieved through a series of exchanges between organisms and their environment. Thus, a person gains information about the environment, on how to affect the environment, and applies that information to the environment, which produces more information, which is then used to affect the environment and so on. Cognitive changes in the organism are mediated by the processes of assimilation and accommodation. According to Piaget, many of the early exchanges between an infant and the environment occur within the context of play. Bruner (1973) expanded upon Piaget's 
conceptualization of play to conclude that play is a forum for the development and the practice of behaviors that are later used in goal directed activity. Belsky and Most (1980) call play a "window" into cognitive development.

A number of other theorists have filled out Piaget's conceptual framework of play. Drawing information from such diverse sources as animal learning studies and psychoanalytic theory, White (1959) synthesized a innovative view of play. Basically, White postulated children control their environment through play, gaining mastery over it, thereby developing a sense of efficacy or competence. This sense of competence provides the motivation for continued play. White (1959) suggested that the motivation to play is evolutionarily adaptive, as play provides information about the environment and how to affect the environment, which increases the chance of survival. Hunt (1965) and Yarrow, Rubenstein, Pederson and Jankowski (1972) extended Piaget and White's conceptualization of play stating that it is intrinsically motivated, not externally imposed, nor a primary biological drive. In summary, the usefulness of play is theorized to be, in part, in its impact on cognitive development, its relationship to feelings of competence, and its ability to produce the motivation to continue exploration, which may enhance an organism's likelihood of survival.

The theoretical foundation built by Piaget, Hunt, White and Yarrow states that play and exploration are manifestations of a child's curiosity about the environment and the need to deal competently with the environment. In addition, they are means of providing informational feedback. The idea that such feedback 
advances cognitive development can be evaluated in light of three more recent interconnected lines of research.

The first line of research examines the relationship between exploratory play and other measures of cognitive competence. The second area looks at the development and changes in exploratory play itself over time. The third line of research examines the differences in exploratory play in delayed and non-delayed children.

If exploratory play is important in the generation of information and the practice of skills that lead to cognitive development, it might be expected that children and young children who show competence in exploratory play would also show competence on cognitive measures. Jennings, Harmon, Morgan, Gaiter and Yarrow (1979), Yarrow, Rubenstein and Pederson (1975) and Hcnir, Speller and West (1985) have all conducted research which has supported this hypothesis. Henir et al. found that competence in spontaneous play was related to later IQ. Yarrow et al. concluded that competence on a measure of exploratory play was related, albeit modestly, with IQ scores approximately three years later. Caruso $(1984,1986)$ found that the degree of sophistication of infant play was related to the degree of sophistication in problem solving tasks at one and two years of age. Thus, it appears that cognitive development and competence are related to exploratory play behavior.

The second line of research relates to the supposition that, if as Piaget proposes, play is part of an interactive process, then play itself should become increasingly complex - incorporating new skills over time. This would seem to be the case according to the work of Belsky 
and Most (1981). Belsky and Most synthesized the information available on early play to postulate a developmental sequence of exploratory play behavior. They then empirically examined this sequence using a sample of 40 infants and toddlers ( $71 / 2$ to 21 months). Empirical evidence thus obtained supported a developmental sequence of exploratory play. Belsky and Most devised a 12-step sequence of development for play. This sequence starts with simple sensorimotor play, such as mouthing and simple manipulation of objects. Subsequently play becomes functional, that is objects are used appropriately (i.e., dialing a play telephone). Children then begin to use objects together in relational play followed by functional-relational play (i.e., placing a spoon in a cup). The exploratory play sequence ends with simple pretend play (i.e., pretend self - drinking from a cup, pretend other - brushing a doll's hair). As would be predicted, children show a decrease in simple play with a simultaneous increase in more complex play behaviors over time. However, it is important to note that this sequence is not simply linear, as a child does not complete one level of play before moving on to the next never to return to previous levels. Rather children may utilize many levels of Belsky and Most's sequence, with the predominant level of exploratory play shifting to more complex play over time.

The third line of research that addresses the theoretical understanding of play developed by Piaget, White, Yarrow, etc. is in part an outgrowth of Belsky and Most's 1980 work. Often using Belsky and Most's play sequence, a number of researchers (i.e. Krakow \& Kopp, 1982; Vietze et al., 1983) began to look at the 
differences in the play of delayed and non-delayed children. Early research indicated that both delayed and non-delayed children obtained the same repertoires of behaviors in the same sequence, with the delayed children progressing at a slower rate of development, as might have been predicted by the work of Zigler (1968). However, upon closer examination, a number of qualitative differences could be seen in the play of delayed and non-delayed children. Krakow and Kopp $(1982,1983)$ found that delayed Down Syndrome children were less socially oriented than non-delayed children, spent more time unoccupied, and showed limited play repertoire, and less monitoring of environment. Vietze, McCarthy, McQuiston, MacTurk and Yarrow (1983) showed that delayed children engaged in less mastery behavior over the environment. Berry and Gwinn (1984) found that normally - developing children were more organized and showed less perseveration in behavior than delayed children. In general, delayed children were less likely to be able to extract information from all sources in environment, including other people. These differences occurred even when children were matched for developmental age (Krakow \& Kopp, 1982). This research supports the theory that play is important in extracting information from environment and that a limitation in this ability may be related to delays in cognitive development.

The research in the relationship of exploratory play to other cognitive competencies, the developmental sequence of play, and the differences in the play of delayed and non-delayed children all support the theoretical importance of play. However, this research supports only that exploratory play is related to cognitive 
development not that it is a causal agent in cognitive development. There may be an underlying factor or a third variable which relates to both exploratory play and cognitive development. This third variable may be rearing practices.

Researchers such as Yarrow et al. (1975) have found significant relationship between rearing practices and IQ. More recent research has focused on the relationship between exploratory play and rearing practices. Caruso (1986) found that children with responsive mothers were more skilled at play. Berry and Gwinn (1984) indicated that the delayed children with mothers responsive to them were less likely to display aimless behavior. Again, these studies all provide correlational evidence for the link between rearing practices, exploratory play, and cognitive development.

Studies, such as those conducted by Caruso (1986), Berry and Gwinn (1984), and Anzalone (1994) have begun to determine specifically which rearing practices, or in other words, which caregiver behaviors might impact on exploratory play and cognitive development. As Anzalone (1994) states, exploratory play functions as a dynamic action system in which features of the individual (attention span, mastery motivation, cognitive ability) interact with features of the environment including social context. Interactions with a primary caregiver form the basis of that social context. Anzalone (1994) found that maternal behaviors such as attention directing and expansion of children's play repertoire were associated with high developmental levels of play, while maternal intrusiveness was negatively correlated with breadth and sophistication of exploratory play. In general, accurate caregiver response and 
sensitivity to infant cues during exploratory play appears to be related to a variety of measures that assess the quality as well as the quantity of infant exploratory play.

An experimental study by Belsky et al. (1980) attempted to demonstrate that a maternal rearing practice that is associated with exploratory play could be altered and that altering this practice would in turn produce a change in infant exploratory play. This study divided children into two groups. One group, the control group, simply received three visits from an observer. In the experimental group, the "observer" would comment ("It's interesting, how you...") when the mother focused her child's attention on a toy in the course of daily interactions. The authors concluded that this intervention increased maternal attention focusing behavior. Additionally, children in the experimental group were more likely to demonstrate sustained attention than control children at the end of the intervention. The general conclusion was that it was possible to affect the maternal behavior related to one skill used in play -sustained attention - and that further this change in maternal behavior affected infant behavior. The authors speculated that maternal attention focusing may help children learn to sustain their own attention. The Belsky et al. study (1980) provides stronger evidence for a causal link between rearing condition and caregiver behavior to exploratory play.

A related line of research (Mahoney, 1988) which demonstrated the reciprocal nature of the exploratory play action system, indicated that mothers of delayed children attempt to modify the interaction pattern with their children (e.g., more 
directive, more physical cues). These modifications can facilitate infant exploratory play if they are appropriately mediated by responsiveness to infant cues, as is the case with typically developing children (Anzalone, 1994). Krakow and Kopp (1982) also indicated that delayed children responded to simplified maternal cues at a higher rate than non-simplified cues.

The research evidence presented thus far demonstrates there is a relationship between 1) exploratory play and cognitive development, 2) between rearing conditions and cognitive development, 3) between rearing condition and exploratory play. There is also preliminary evidence for a causal link between some aspects of rearing conditions and exploratory play. As stated previously, this research as a whole supports the theoretical framework proposed by Piaget and expanded by White, Hunt, and Yarrow - exploratory play is an important factor in the process of cognitive development. The support provided by this research is limited in some ways. Evidence of a direct causal link between exploratory play and cognitive development has not been found and there is only limited evidence for a causal relationship between exploratory play and the caregiver behavior aspect of rearing practices.

A productive avenue for future research may be to impact upon caregiver variables in order to affect exploratory play. For example, we have evidence that maternal actions are related to infant exploratory behavior, moreover we know that it may be possible to impact upon maternal actions and see a change in infant behavior. The present study attempts to provide further evidence 
for a causal link between caregiver behavior and infant exploratory play behavior. This research question is examined more fully in the current study. As part of this question, it becomes important to explore more fully which maternal behaviors impact on infant exploratory play as well as how to promote maternal behaviors which are shown to promote competence in exploratory play. Prior research can provide some directions in this area. For example, Krakow and Kopp $(1982,1983)$ point out as delayed children attend less to the social information available in their environment, it might be productive for parents to take increased responsibility for initiating and structuring social interaction.

The current study is experimental. The parents of one group of children are trained to initiate and structure social interaction with their delayed children while the other group receives general information on parenting. The impact of training on parent behavior and child behavior, particularly exploratory play, is then examined. This study attempts to provide information on a casual link between parent behavior and exploratory play. It also attempts to provide indirect evidence for the importance of the role exploratory play has in cognitive development. This type of study may also be useful in that it is compatible with the current emphasis on training parents to be the provider of services to children needing early intervention.

\section{Research Questions}

This study focuses on the design of an intervention conducted with developmentally delayed children and their parents. It is hypothesized that providing parents with training on strategies that 
are related to exploratory play competence would lead to an increase in use of those strategies by parents which in turn, leads to higher developmental levels of play and exploratory competence in children. Specifically it was predicted that children who participate in the training group would have a higher developmental level of play than children whose caregivers do not receive training on facilitating exploratory play. Additionally it was expected that the children in the training group would display a higher quality of exploratory play in terms of greater breadth, increased sophistication, and a faster behavioral tempo. Also children in the training group were predicted to have a greater quantity of exploratory play as shown by increased total exploration and increased percentage of time spent in exploration post-training. It was also predicted that caregivers who participated in the training group would display more behaviors that facilitate infant exploratory play (i.e., attention directing, expanding, organizing, supporting infant) and less behaviors that inhibit exploratory play (i.e., intruding, initiating, and removing toys) at the conclusion of the intervention. The relationship between caregiver behavior and infant exploratory play was also examined pre- and postintervention.

\section{Method}

\section{Participants}

The participants in this study were 29 young children, 18 males and 11 females, as well as their primary caregivers. The mean chronological age of the children participating in the study was 18 
months. Fifteen children and caregivers were assigned to the exploratory play training group, while 14 children and caregivers comprised the general information group. In all cases the primary caregivers were mothers or foster mothers. The children and the primary caregivers of the children were recruited through six regional early intervention centers in Rhode Island and Massachusetts. All of the participating children met the early intervention criteria for a diagnosis of developmentally delayed. Additionally, the Bayley Scales of Infant Development - Second Edition (BSID-II), was administered to obtain information on the mental developmental level of the participating children. The mean developmental level of the children in the study as measured by the BSID-II was 14 months. Caregivers with known histories of mental illness such as depression or substance abuse were not asked to participate in the present study.

As developmental performance in infancy relates to socioeconomic status (Anzalone,1994), information on marital status, caregiver education, employment, as well as infant birth order were obtained via a brief questionnaire and record review. This questionnaire is available in Appendix A.

\section{Instrumentation}

\section{Developmental Assessment. The Bayley Scales Of Infant}

Development-2nd Edition, Mental Development Index (BSID-II, MDI) was administered to each child in the second week of the intervention. The BSID-II was used to describe the global developmental level of the sample. The BSID-II is the most recent revision of one of the most frequently used measurements of infant 
development. According to the Psychological Corporation's (1993) review of the statistical properties of the BSID-II (MDI), the revision was well standardized using a national sample with excellent testretest reliability $(r=.91)$ and concurrent validity with the McCarthy Scales of Children's' Ability $(r=.989)$ as well as the WPPSI-R ( $r .=.992)$

Summary of Coding. Pre-test and post-test videotapes were analyzed for children's developmental level of play, quality of play, and quantity of play using predetermined behavior checklists on a 15 second interval basis for 10 minutes (five minutes of independent play, 20 intervals; five minutes of play with caregiver, 20 intervals). Prior research (Anzalone,1994) has determined that an infant can initiate and execute a play action in 15 seconds, thus 15 seconds was the unit of time sampling for all coding. Caregiver actions were also analyzed using the same approach (five minutes of play with child, 20 intervals). The coding system used to derive these variables were based on methods described by Anzalone (1994) and Caruso (1990, 1993). Acceptable levels of interrater reliability $(K=0.86$ for caregiver behavior, $\mathrm{K}=0.88$ for infant behavior), as defined in Bordens and Abbott (1992), were obtained using pilot children prior to coding data tapes. Although the behavior coding strategies used in this study have been used successfully in previous research (i.e., Anzalone,1994; Belsky \& Most, 1981; Caruso, 1990;1993), no additional reliability and validity data are available at this point. Samples of coding sheets used are available in Appendixes B and C. Infant Exploratory Play.

Developmental Level Coding. Developmental level of play was measured by both a Spontaneous Mastery Score which is the highest 
level of play that an infant is able to sustain (Hrncir et al., 1985) and Average Developmental Level (weighted average of all exploratory play behaviors used). Play levels were given weighted numeric values based on sequence in the Belsky and Most Scale (1981) e.g., mouthing $=1$, simple manipulation $=2$ and so forth. The highest level of play utilized in each of the 15 second intervals were summed and divided by the number of intervals to obtain the Spontaneous Mastery Score (SMS). The weighted score for each exploratory behavior was summed and divided by the number of behaviors to obtain an Average Developmental Level (ADL). Operational definitions of all variables and the behaviors used in their derivation are available in Table 1.

Table 1

Operational Definitions of Developmental Level Variables and Behaviors used to Derive Those Variable

Behavior name

Mouthing

Simple Manipulation

Functional

Relational

Functional-Relational

Enactive Naming
Definition (Weighted Value)

Place or hold object in mouth (1).

Visually guided manipulation (2).

Visually guided manipulation that is appropriate for a particular object (3).

Place two objects in an inappropriate relationship

Place two objects in an appropriate relationship

Approximate pretense activity without confirming evidence of pretense behavior (6). 
Pretend Self

Pretend Other

Developmental Level Variables

Spontaneous Mastery Score (SMS)
Pretense behavior directed toward self with confirming evidence (7).

Pretense behavior directed toward other with confirming evidence

Weighted score for the highest

level of exploratory play in each interval summed and divided by the number of intervals.

Average Developmental Level Total of weighted scores of all (ADL) exploratory behaviors divided by the number of exploratory behaviors used.

Exploratory Quality Coding. Exploratory quality coding involved examining a number of exploratory strategies that included: visual examination, mouthing, gross motor exploration, fine-motor exploration, manipulate object to look, and combining two objects in a relationship. Operational definitions for exploratory quality variables are available in Table 2. These behaviors yielded four variables: Total Breadth, Caruso Breadth, Sophistication Ratio and Behavioral Tempo. Breadth was defined as the total number of different exploratory play behaviors a child used.

Table 2

Operational Definitions of Exploratory Behavior Used to Determined Quality and Quantity of Exploratory Play and Variables Derived From Those Behaviors

Exploratory behaviors Squeeze
Definition

Compress object with fingers while holding. 
Jab with Finger

Rub Object Surface

Finger Manipulate

Visual Examination

Manipulate to Look

Shake Object

Bang Object

Rub on Table

Drop Object

Throw Object

Pull Apart/Twist

Combining Objects

Mouthing

Quality

Total Breadth
Press object against table with finger(s).

Feel texture of object surface with finger(s).

Move or turn object with fingers.

Look at object(s) without touching.

Look carefully at object while holding.

Move object back and forth in air while holding.

Repeatedly hit object against table.

Move object back and forth across table.

Purposefully release grasp of object and drop.

Toss object using arm or wrist movement.

Using two hands, pull or twist objects in two directions.

Place two objects in a relationship.

Place or hold object in mouth.

Number of different exploratory behaviors

used at least once. Includes the following variables: mouthing, squeeze, jab with finger, rub object surface, finger manipulate, visual examination, manipulate to look, shake, bang, rub on table, drop/throw, pull apart/twist.

Also includes functional, relational, functional-relational, enactive naming, pretend self, pretend other. (Note: combining $=$ relational + functional-relational). 
Number of different exploratory behaviors used at least once. Includes the following variables: mouthing, squeeze, jab with finger, rub object surface, finger manipulate, visual examination, manipulate to look, shake, bang, rub on table, drop/throw, pull apart/twist, combining.

Sophistication Ratio Number of sophisticated exploratory behaviors (squeeze, jab with finger, rub surface, finger manipulate, combining, manipulate to look) divided by the number of unsophisticated exploratory behaviors (visual examination, mouthing, shake, bang, rub on table, drop, throw, pull apart/twist).

Behavioral Tempo. Total of all exploratory behaviors divided by total time engaged in exploring.

Quantity

Total Exploring Total of all exploratory behaviors.

Exploration Time Percentage of time available spent in exploration.

The Sophistication Ratio was a ratio of the frequency of sophisticated exploratory behaviors divided by the frequency of unsophisticated exploratory behaviors. The determination of a play behavior as sophisticated or unsophisticated and the use of a sophistication ratio was based on previous findings of Caruso (1990, 1993) and Anzalone (1994). Behavioral Tempo was defined as ratio of total exploratory play behaviors to time spent in exploration.

Exploratory Quantity Coding. Exploratory quantity again utilized the exploratory behaviors that are presented in Table 2 . These behaviors were used to calculate two quantity variables: the 
total number of exploratory behaviors an infant used and percentage of the time available that the infant engaged in exploration.

Caregiver Behavior Coding. Caregiver coding attempted to capture information on caregiver behaviors that have previously been shown to either facilitate or inhibit infant exploratory play. Using Anzalone's (1994) coding scheme, which was based on the work of Fiese (1990), these behaviors were classified into nine categories including the following: Social, Follow/Imitate, Support, Expand, Intrude, Initiate, Remove Toy, Attention Directing, Organize. Operational definitions of these behaviors are available in Table 3. Table 3

Operational Definitions of Caregiver Variables

Caregiver behavior Attention Directing

Organize

Follow/Imitate

Support

Expand

Intrude
Definition

Caregiver uses gestures or actions to redirect infant's attention to activity infant was previously attending to.

Caregiver's actions are not directed to infant's exploration but are preparatory.

Caregiver does same action child initiates.

Caregiver provided support for infant's goals while the Infant is engaged in exploration.

Caregiver expands upon infant's play through demonstration.

Caregiver interferes by interrupting infant's exploration to teach by preventing infant from continuing own exploratory activity. 
Initiate

Caregiver introduces new object-not in response to infant cue.

Remove Toy

Caregiver removes toy from infant but does not explore or demonstrate it use.

Social Interaction not object focused

Follow/imitate, Support, Expand, Organize and Attention Directing would be considered facilitative behaviors, while Intrude, Initiate, And Remove Toy may be classified as inhibitory. Social behavior is classified as neutral. Measurement of each of these nine categories consisted of frequency counts of the behaviors.

Procedure

Regional early intervention program directors selected potential participants, using the criteria outlined for participant inclusion, and gave potential participants a letter from the experimenter describing the study (See Appendix D). Using identical procedures, the investigator conducted all sessions at all six sites. After individuals expressed interest in the study, the experimenter telephoned each caregiver to describe the study in detail and to ascertain willingness to participate in it. Written consent was obtained at each group's first meeting. Samples of the letter introducing the study and the consent form are available in Appendix D and Appendix E. Additionally any consent forms typically used by individual regional programs were completed during the initial session. After caregivers were contacted and the number of caregivers interested in group participation was known, group assignment was determined. With six or more potential child/caregiver pairs in one early intervention program, random 
assignment of pairs to one of two groups (with a minimum of three participants) occurred without replacement. When less than six potential participants were available at one site, they were, as a group, assigned to a condition (via coin toss). When possible a subsequent group at that site was assigned to the other condition. One type of group focused on teaching caregivers specific skills to facilitate their children's play. The other type of group, a comparison group, focused on providing caregivers with general information on different areas of development (i.e. social, physical, cognitive).

Sequence of Eight Week Intervention. This study was conducted at the early intervention centers that served as the base for recruitment of participants. The study took place over an eight week period for each group of participants. An interpreter was present during all sessions for those caregivers whose primary language was not English.

In the first week, the purpose of the study was reviewed and introductions were made in both groups. During the second week each child's developmental age was individually assessed using the Bayley Scales Of Infant Development-2nd Edition, Mental Scale (Psychological Corporation, 1993). In the third week, pre-test data on the play behavior of the children and on the child/caregiver interaction were collected using a standardized set of toys via video camera for all groups. First each child was videotaped playing independently for five minutes. The child and his/her caregiver were then videotaped together for an additional five minute period. The instructions used to introduce the different play segments are available in Appendix $F$. 
The set of standardized toys selected for use in the present study has been used in previous research using similar measures of exploratory play and has been shown to provide the potential for sustained play and diverse exploration (Anzalone,1994; Belsky \& Most, 1981; Caruso, 1993). Additionally these toys are commercially available and are safe for children who fall within the developmental range used in this study. A list of the toys used is available in Appendix G.

In the following four weeks the primary caregivers of children in the exploratory play group were taught to facilitate their child's play. First, they were taught to recognize when their child has lost interest in the age appropriate toys provided (non-attention). Then they were taught strategies, such as verbal and physical cues, to reengage their child's interest. In the last two weeks of the intervention phase of the study, caregiver's learned how to expand their infant's play repertoires using skills including verbal descriptions and praise. This phase of the intervention was based in part on the Nursing Child Assessment Teaching Scale (Barnard, 1988). For example, caregivers were encouraged to use both verbal descriptions and modeling while demonstrating a use of a toy to their children. Caregivers assigned to the general information group were given information on development (one week each for motor, cognitive, language and social development). An overview of the sequence of the eight weekly sessions for both groups is provided in Appendix H. A summary of the content provided to each group during the eight weeks is included in Appendix I. In the eighth week, post-test observations of the behavior of the children, their 
caregivers, and infant/caregiver interactions using the standardized set of toys were again recorded using a video camera. To qualitatively assess the effectiveness of the intervention, participants were asked if they would be willing to complete a brief questionnaire (see Appendix J) regarding the intervention at it's conclusion.

Format Of Intervention Sessions. All subjects participated in 90 minute weekly sessions. During the first 20 minutes, the topic for the week was introduced. The children and their caregivers then rotated through a series of play stations. Toys available at the different play stations were developmentally appropriate. The stations used included constructive toys, art media, manipulatives, as well as material for pretend play. While the children were at different stations, the caregivers in the exploratory play training group were provided with specific suggestions to facilitate the children's play. In the general information group, caregivers heard how their children's performance reflects developmental skills. In the last ten minutes of the sessions, a summary of the session was given and caregivers were encouraged to use the information they gained at home. During the pre-test and post-test weeks (weeks 3 and 8) the set of standardized toys were presented for videotaping as an additional play station.

\section{Results}

Parallel sets of analyses were used to examine data obtained from the caregivers and children involved in the study. In other words, the dependent variables based on caregiver behavior in the 
two group across time (Social, Follow/Imitate, Support, Expand, Intrude, Initiate, Remove Toy, Attention Directing, Organize) were summarized, compared and analyzed for statistically significant differences in one set of analyses. In the other set of analyses, the differences between the children of the two groups across time on the dependent variables related to infant behavior (i.e., SMS, ADL, Sophistication Ratio, Breadth, Behavioral Tempo, Total Exploring, Exploration Time) were summarized, compared and analyzed for statistical differences. Child behavior was examined both when children were playing independently and when children were interacting with their caregivers. In the case of significant differences, ANOVAs were used to assess each dependent variable's contribution to the effect. Additionally the relationship between caregiver behavior and infant behavior was examined pre- and postintervention using Pearson product moment correlations.

To provide background information, demographic and descriptive data will first be presented. Remaining results will be presented to address the major research questions under exploration. These questions include the effects of group participation on caregiver and child behavior as well as the relationship between caregiver behavior and child play behavior.

\section{Demographic and Descriptive Data}

All caregivers and their children were involved in regional early intervention programs in Rhode Island and Massachusetts. English was the primary language for 24 of the caregivers, with four caregivers using primarily Spanish and one caregiver using primarily Portuguese. The majority of the mothers participating in the study 
were married (65\%). Forty-one percent of the caregivers indicated that they had some college, a college degree or had education beyond college. Forty-five percent of the caregivers had a high school education or less. Sixty-five percent of the caregivers were not employed at the time of the study. Skilled labor, unskilled labor and professional occupations were represented among those caregivers that were employed or those who indicated their previous employment. Thirty-three percent of the sample received public assistance (i.e. AFDC benefits, SSI benefits). Fifty-three percent of the children in the sample were first born, forty percent were later born. The birth order of two children was unknown due to foster placement status. Additional descriptive information on the children in each group is available in Table 4.

Table 4

Descriptive Information on Children

\begin{tabular}{lll}
\hline & $\begin{array}{c}\text { Exploratory Play } \\
\text { Group 1 }\end{array}$ & $\begin{array}{c}\text { General } \\
\text { Group 2 }\end{array}$ \\
\hline Mean Age (months) & 18.9 & 19 \\
$\begin{array}{l}\text { Mean Developmental } \\
\text { (months, BSID-II) }\end{array}$ & 13.8 & 15.8 \\
Gender & 7 males & 11 males \\
& 7 females & 4 females \\
Birth Order & 8 first born & 7 first born \\
& 6 later born & 6 later born \\
& & 2 unknown \\
\hline
\end{tabular}

As wide ranges of caregiver education (less than high school to graduate degrees) and employment (unemployed to professional occupations) were represented within the current sample and as 
Anzalone (1994) found no significant effects of demographic variables (child gender, birth order, maternal education, work status) on play and developmental variables, current analyses did not control for demographic effects.

The first step in the analyses was to summarize the data using descriptive statistics. In order to choose measures of central tendency and variability, the frequency distributions of the dependent variables for both children and caregivers were screened for skewness, kurtosis and the presence of outliers. Generally the distribution of scores was normal, thus, means and standard deviations were calculated for the behavior of caregivers in the two groups (exploratory training and general information) as well as for the behavior of the children in the two groups (exploratory training and general information) on pre- and post- intervention data. These means are presented in Tables 5, 6 and 7. Additionally as the variable Sophistication Ratio contained two outliers, median scores for this variable are also presented.

Table 5

Pre and Post-Test Means and Standard Deviations for Caregiver Behavior by Treatment Group

\section{Exploratory Play General Information}

Behavior Post Pre Post Follow/Imitate Pre 1.7

0.9 2.9

SD $\quad 2.4$

2.9

1.2

3.0

n

15

14

14

14

Support

$\begin{array}{ll}\underline{\mathrm{M}} & 3.9 \\ \underline{\mathrm{SD}} & 3.1 \\ \underline{\mathrm{n}} & 15\end{array}$

5.5

4.1

2.9

3.6

2.7

2.1

14

14

14 
Expand

$\begin{array}{lllll}\underline{\mathrm{M}} & 9.5 & 12 & 9.7 & 12 \\ \underline{\mathrm{SD}} & 6.6 & 5.3 & 9.4 & 10.2 \\ \underline{\mathrm{n}} & 15 & 14 & 14 & 14\end{array}$

Attention
Intrude

Direct. $\underline{\mathrm{M}}$

2.9

2.1

1.6

1.9

SD $\quad 3.8$

1.9

1.7

1.6

n 15

14

14

14

$\begin{array}{ll}\underline{\mathrm{M}} & 4.5 \\ \underline{\mathrm{SD}} & 4.3 \\ \underline{\mathrm{n}} & 15\end{array}$

1.8

4.9

4

2.1

14

6.5

4.3

14

14

Initiate

M $\quad 10.1$

9.5

6.8

8.1

SD $\quad 6.4$

5.6

4.3

4.4

n 15

14

14

14

Remove Toy

$\begin{array}{ll}\underline{\mathrm{M}} & 0.4 \\ \underline{\mathrm{SD}} & 0.8 \\ \underline{\mathrm{n}} & 15\end{array}$

Organize

$\begin{array}{ll}\underline{\mathrm{M}} & 4.1 \\ \underline{\mathrm{SD}} & 3.4 \\ \underline{\mathrm{n}} & 15\end{array}$

0.3

0.4

0.6

SD $\quad 0.8$

0.6

0.7

0.8

14

14

14

Socia1

$\begin{array}{ll}\mathrm{M} & 3.9 \\ \underline{\mathrm{SD}} & 4.9 \\ & 15\end{array}$

4. 1

4.5

4.1

2.4

3.2

2.4

14

14

14

n 15

4.8

3.6

5.6

3.0

3.7

1.5

14

14 14

All caregivers engaged in interactions with their child for as long as their child remained at the videotaping play station. No caregiver terminated the interaction prior to the conclusion of the five minute interval unless their child left the play station and could not be directed back to it. The caregiver behaviors that occurred with the highest frequency both before and after the intervention included expanding upon a child's play and introducing new objects into play (Initiate). The behavior that occurred with the lowest frequency prior and subsequent to the intervention was the removal of a toy from a child. 
Table 6

Pre and Post-Test Means and Standard Deviations for Child Behavior during Independent Play by Treatment Group

\section{Exploratory Play General Information}

Behavior

Pre

Post
Pre

1.7

Ratio

$\begin{array}{ll}\underline{\mathrm{M}} & 1.3 \\ \underline{\mathrm{SD}} & 1.4 \\ \underline{\mathrm{n}} & 15 \\ & 0.8\end{array}$

1.7

2.8

14

1.0

1.3

0.8 Median $\quad 0.8$

4.2

1.3

0.8

14

Behavioral

$\begin{array}{lll}\underline{\mathrm{M}} & 3.9 & 4.2 \\ \underline{\mathrm{SD}} & 0.8 & 1.3 \\ \underline{\mathrm{n}} & 15 & 14\end{array}$

14

1.4

Tempo

$\begin{array}{lllll}\underline{\mathrm{M}} & 92.0 & 95.3 & 81.8 & 90.0 \\ \underline{\mathrm{SD}} & 12.4 & 9.9 & 24.4 & 21.6 \\ \underline{\mathrm{n}} & 15 & 14 & 14 & 14\end{array}$

Total

M $\quad 70.7$

76.6

54.8

70.4

Exploring

SD $\quad 19.1$

25.2

25.8

23.9

n 15

14

14

14

Total

Breadth

M $\quad 9.5$

SD $\quad 1.4$

n 15

Caruso

Breadth

M $\quad 8.5$

SD $\quad 0.9$

n 15

Spontaneous $\quad \underline{M} \quad 2.7$

Mastery Score $\underline{\text { SD }} 0.8$

n 15

Average

Developmental

M $\quad 2.1$

$\underline{S D}$

0.1

n 15

Level
12.1

14

10.3

1.5

14

3.6

1.1

14

2.6

0.5

14
9.9

1.8

14

8.7

1.5

14

11.1

1.9

14
3.5

1.1

14

3.8

1.2

14 
This behavior often occurred when a child was mouthing a toy. Other behaviors that occurred relatively infrequently included imitating a child's actions and attempting to regain a child's attention to a previously explored object.

All of the children engaged in exploratory play both independently and when with their caregiver, however not all children sustained five minutes of independent play or five minutes of play with caregiver. In general, wide variability was present in variables that measure the quantity of play (Exploration Time and Total Exploring). The play of the children in both groups centered mainly around simple exploration. The children explored toys primarily through mouthing, simple manipulation, using objects functionally and beginning to combine objects with less frequent instances of pretense play. This is evident as the Average Developmental Level of all children ranged between 2 and 6 both before and after the intervention.

Table 7

Pre and Post-Test Means and Standard Deviations for Child Behavior during Play with Caregiver by Treatment Group

\section{Exploratory Play General Information}

Behavior Pre Post Pre Post Sophistication

0.7

0.8

0.8

1.3

Ratio

$\underline{\mathrm{SD}}$

0.6

n

15

M $\quad 3.3$

SD $\quad 1.8$

n $\quad 15$

Exploration

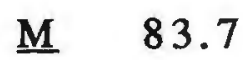

0.5

0.6

0.3

Behavioral

Tempo

14

14

14

3.6

3.4

3.4

0.7

0.9

1.2

14

14

14

90.4

78.2

98.2 


\begin{tabular}{llllll} 
Time(\%) & $\underline{\mathrm{SD}}$ & 23.7 & 916.6 & 35.6 & 4.2 \\
Total & $\underline{\mathrm{n}}$ & 15 & 14 & 14 & 14 \\
Exploring & $\underline{\mathrm{M}}$ & 58.1 & 63.4 & 53.6 & 66.7 \\
& $\underline{\mathrm{SD}}$ & 28.3 & 19.4 & 29.5 & 22.9 \\
& $\underline{\mathrm{n}}$ & 15 & 14 & 14 & 14 \\
Total & $\underline{\mathrm{M}}$ & 8.8 & 11.0 & 9.1 & 10.7 \\
Breadth & $\underline{\mathrm{SD}}$ & 2.4 & 3.8 & 3.5 & 2.9 \\
& $\underline{\mathrm{n}}$ & 15 & 14 & 14 & 14 \\
Caruso & $\underline{\mathrm{M}}$ & 7.6 & 8.9 & 7.6 & 9.1 \\
Breadth & $\underline{\mathrm{SD}}$ & 2.0 & 3.2 & 3.2 & 2.4 \\
& $\underline{\mathrm{n}}$ & 15 & 14 & 14 & 14 \\
Spontaneous & $\underline{\mathrm{M}}$ & 3.0 & 3.6 & 3.4 & 3.8 \\
Mastery Score & $\underline{\mathrm{SD}}$ & 1.0 & 1.1 & 1.1 & 1.3 \\
& $\underline{\mathrm{n}}$ & 15 & 14 & 14 & 14 \\
Average & $\underline{\mathrm{M}}$ & 2.5 & 2.7 & 2.8 & 2.9 \\
Developmental & $\underline{\mathrm{SD}}$ & 0.6 & 0.5 & 1.3 & 0.7 \\
Level & $\underline{\mathrm{n}}$ & 15 & 14 & 14 & 14 \\
\hline
\end{tabular}

The mean Average Developmental Level was roughly equivalent to play levels between simple and functional manipulation. The highest average exploratory play behavior in each interval (SMS) was roughly equivalent to play levels between functional manipulation and relational play. However most children, when playing independently, used at least four different behaviors to explore toys (Total Breadth).

Multivariate Analyses of Variance

The second step in the analyses of the data was to test for significant group differences using two $2 \times 2$ MANOVAs (Group: 1) Specific Training 2) General Information $x$ Time: 1) Pre-intervention 2) Post- intervention). One MANOVA was used with the caregiver variables, while a second MANOVA was used with the child 
variables. The MANOVA is the analysis of choice in the present study because there are several dependent variables for both caregivers and children and because there is evidence (e.g., Anzalone, 1994) that these variables may be correlated.

Prior to using the MANOVA the data were checked to ensure that assumptions underlying multivariate statistics were met. This included examining frequency distributions for outliers, skewness, and kurtosis. Given the presence of two outliers (as defined in Tabachnick \& Fidell, 1989) in the distribution of variable "sophistication ratio", this variable was eliminated from subsequent analyses.

The effect of Time, Group, and the Interaction of Group and Time on combined caregiver behavior dependent variables was assessed using Wilks' criterion. The combined caregiver dependent variables were not significantly effected by time, $F(9,45)=0.85$, n.s., group assignment, $F(9,45)=0.82$, n.s, nor the interaction between group assignment and time, $F(9,45)=0.85$, n.s. As the multivariate analysis of variance did not indicate significant differences between groups or over time and as the interaction of group and time did not significantly impact caregiver variables, no follow-up tests were conducted.

Using Wilks' criterion, the combined child dependent variables were significantly effected by time, $F(14,40)=2.69, \underline{p}<.05$. However neither group assignment, $F(14,40)=1.59$, n.s, nor the interaction between group assignment and time, $F(14,40)=1.03$, n.s., significantly effected the combined dependent variables measuring child behavior. To examine the impact of the main effect 
of time on individual dependent variables a series of univariate ANOVAs were used as follow-up tests.

Univariate Analyses of Variance

As there were no effects of Group, Time, or Group $x$ Time interaction on caregiver dependent variables in the multivariate analysis, no follow up test were considered. Additionally neither Group nor the Group $x$ Time interaction significantly effected child play variables. Therefore, only the effect of Time (Time 1, Time 2) on individual child play variables was considered in a series of univariate analyses of variance (see Appendixes $K$ and $L$ ).

When examining the results of the univariate analyses, it is clear that time significantly affected the Breadth of children's play. Breadth is considered to be an indicator of quality of play. This affect was evident both when the child was playing independently and during interaction with caregiver. When interpreted in conjunction with the means of child behavior during independent play, Caruso Breadth increased significantly across time, $F(1,53)=$ $17.59, \mathrm{p}<.05$ as did Total Breadth, $\mathrm{F}(1,53)=17.70, \mathrm{p}<.05$.

Additionally when the behavior of children during interaction with caregivers is considered, Caruso Breadth again increased significantly across time, $\mathrm{F}(1,53)=6.94, \mathrm{p}<.05$ as did Total Breadth, $\mathrm{F}(1,53)=$ $9.71, \mathrm{p}<.05$. Other dependent variables considered to measure the quality of a child's play also increased over time. When playing independently, children's Spontaneous Mastery Score, $F(1,53)=$ $4.49, \underline{p}<.05$, and Average Developmental Level, $F(1,53)=4.31$, p< .05, increased significantly over time. 
While several variables related to quality of play changed over time, only one variable related to quantity of play changed over time. This variable, Exploring Time, was significantly different across time during the children's interaction with their caregivers, $F(1,53)$ $=4.70, \underline{p}<.05$. When interpreted in conjunction with the means, this indicated that children spent more time in exploration when mother was present after the four week intervention period. None of the other variables that directly measure quantity of play (Total Exploring with caregiver; $\mathrm{F}(1,53)=1.84$, n.s; Total Exploring When Alone, $\mathrm{F}(1,53)=3.67$, n.s.; Exploring Time When Alone, $\mathrm{F}(1,53)=$ 1.35 , n.s.) or variables that rely in part on quantity (Behavioral Tempo with caregiver; $F(1,53)=.33$, n.s.; Behavioral Tempo when alone, $F(1,53)=2.57$, n.s., changed significantly over time. Graphs depicting the means for those variables that differed significantly over time in the univariate analysis are in Appendix M.

Relationship Between Child and Caregiver Behavior

Pearson product-moment correlations were calculated to explore the degree of relationship between caregiver and child behavior before and after the intervention period. The Pearson product-moment correlation is used as all variables are continuous. All correlation coefficients presented are statistically significant.

Prior to the intervention, the children's exploratory play behavior when playing independently was not, in general, related to the patterns of behavior that the mothers demonstrated when playing with their children. For example, mother's attention directing behavior was not related to any of the variables that measured independent child play. An exception to this was the 
relationship of the variable Expand to child behavior. The degree to which mothers expanded upon their children's play was positively related to measures of play in both groups prior to the intervention. In the group (Group 1) that would later receive training specifically related to exploratory play, the mother's expansion of play was related to increased sophistication in the child's play, $\mathrm{r}=.7, \mathrm{p}<.05$. In the group (Group 2) that later received general information, expansion of play was related to increased time spent in exploration, $\mathrm{r}=.57, \mathrm{Q}<.05$. Additionally, in Group 1, mother's organization of materials in preparation of play activities was related to an increase in breadth of infant play, $r=.53, \underline{p}<.05$, while removal of toys by mother was related to a decrease in breadth, $r=.-.6, p<.05$.

A number of relationships were evident between child behavior and caregiver behavior when the dyad was engaged in play together prior to the intervention. Caregiver's support and expansion of their children's play was positively related to both quality and quantity of play in both groups of children. For example, expansion was positively correlated to Exploration Time, $r=.56, \underline{p}<.05$, Total Exploring, $\mathrm{r}=.53, \mathrm{p}<.05$, Total Breadth, $\mathrm{r}=.69, \mathrm{p}<.05$, and Caruso Breadth, $I=.61, \underline{p}<.05$, while Support was positively related to Behavioral Tempo, $\mathrm{r}=.56, \mathrm{p}<.05$ and Total Exploring, $\mathrm{r}=.54, \mathrm{p}<.05$ in Group 1. In Group 2, Support was positively related to Exploration Time, $\mathrm{r}=.75, \mathrm{p}<.05$, Total Exploring, $\mathrm{r}=.56, \mathrm{p}<.05$, Total Breadth, $\mathrm{r}=.71$, $\mathrm{p}<.05$, and Caruso Breadth, $\mathrm{r}=.6, \mathrm{p}<.05$, while expansion of play was related to sophistication of play, $r=.87, p<.05$ and the total amount of exploration, $\mathrm{r}=.65, \underline{\mathrm{p}}<.05$. 
Subsequent to the intervention, there were no significant relationships noted between child behavior when playing independently and caregiver behavior in the group that received general developmental information (Group 2). Interestingly several relationships between caregiver behavior and child behavior (when playing independently) emerged in the group that received specific information regarding facilitation of exploratory play subsequent to the intervention (Group 1). However, contrary to prior prediction, behaviors considered facilitative were negatively related to variables that relate to quantity of exploration. Thus imitation was negatively related to exploration time, $r=-.74, \underline{p}<.05$, and caregiver expansion of play was related to a decrease in the amount of total exploring a child did, $\mathrm{r}=-.56, \underline{\mathrm{p}}<.05$ as well as to a decreased Behavioral Tempo, $\mathrm{r}=-.57, \mathrm{p}<.05$.

When the children in Group 1 were engaged in play with their caregivers, subsequent to intervention, the caregiver behavior of initiating a new play sequence was related to decreased sophistication in child's play, $r=-.67, \mathrm{p}<.05$. When the children of Group 2 engaged in play with caregivers subsequent to the intervention, a different pattern of results emerged. Caregiver social behavior was positively associated with the quantity variable of Total Exploring, $\mathrm{r}=.62, \mathrm{p}<.05$, as well as Behavioral Tempo which also, in part, examines the number of play sequences a child uses, $r=-.57$, $\mathrm{p}<.05$.

\section{Parent Responses to Group Participation}

Sixteen parents returned questionnaires asking for feedback on various aspects of group participation. The returned questionnaires 
included feedback from parents assigned to both intervention groups. Generally, across groups, parents valued the opportunity to interact with other parents and they valued having their children "socialize" with other children. Additionally several parents indicated that the group helped them realize the importance of play, helped them play "better" with their children, or helped them choose "better" toys. Some parents reported changes in behavior related to the training they had received. For example, a mother in the exploratory training group reported that she had learned, "letting W. play his way, not forcing him." A mother in the general information group indicated that she had learned "what to do to help motor skills." It appears that while at least some parents learned strategies specifically related to their group assignment, these strategies were not as valued as opportunities to interact with others. Additionally more parents reported increased understanding of the importance of play in general as opposed to increased understanding of specific strategies to promote play, regardless of group assignment.

\section{Discussion}

The finding of this study are discussed in relation to two central research questions: (a) the effect of group participation on caregiver and child behavior as well as (b) the relationship between caregiver and child exploratory play behavior before and after the intervention period. In addition, the exploratory behavior of the children in the present study is compared to prior findings regarding exploratory play in developmentally delayed children. The Effect of Group Participation On Caregiver Behavior And Child Exploratory Play 
The hypothesis that providing parents with training on strategies that are related to exploratory play competence in children leads to an increased use of those strategies was not supported by the results of the current study. Caregiver behavior on variables previously shown to be related to child exploratory play competence (Anzalone, 1994) did not change over the course of the current intervention. This lack of change was noted in both the group that received general information on development and in the group that received specific training on these behaviors. Caregivers who participated in the exploratory play training group did not display more behaviors that facilitate infant exploratory play (i.e., attention directing, expanding, organizing, supporting) or less behaviors that inhibit exploratory play (i.e., intruding, initiating, and removing toys) at the conclusion of the intervention.

In addition, the hypothesis that changes in the behavior of caregivers who received specific training regarding the facilitation of exploratory play leads to higher developmental levels of play and exploratory competence in their children was not supported.

Children who participated in the specific training group did not demonstrate a higher developmental level of play, an increased quantity of :exploration, or a greater breadth of exploration than children whose caregivers received training on general development. Children in the training group and children in the general information group did not differ significantly in terms of quality of exploratory play or in quantity of exploratory play subsequent to intervention. 
Although the exploratory behavior of children in the general information group did not differ from that of children in the specific training group, results of the current study indicate that children's exploratory play behavior changed over time. This change was evident both when children were playing independently and when playing with their caregiver. There was a significant change over time in a number of variables related to quality of exploratory play behavior (Breadth, Average Developmental Level When Alone, Spontaneous Mastery Score When Alone). Interestingly, only one variable related to quantity, Exploring Time when with caregiver, changed over time. Anzalone (1994) suggests children's behavior when alone is a more comprehensive indicator of the exploratory system than is their behavior when with caregivers. Thus it appears that the quality of play demonstrated by the developmentally delayed children in this study improved over time. That is, these children explored toys using a greater variety of behaviors and incorporated higher levels of exploration into their play. This finding is important as previous studies indicated that while children with developmental delays progressed through the exploratory play sequence, albeit at a slower rate, concerns with quality of play remained (Krakow \& Kopp, 1982; 1983).

The present study suggests that it may be possible to increase the quality of infant exploratory play with a group intervention, however that intervention may not need to incorporate strategies that are specifically geared toward facilitating exploratory play. Eight weekly session that focus on the importance of play and provide opportunities for caregivers to play with their children using 
developmentally appropriate toys may lead to an increase in the quality of child play whether specific information regarding exploratory play is provided or not. Additionally, the information mothers gained by watching other caregivers playing with their children and the support obtained from interacting with others may also be related to change. In other words, participation in either group of the present study may have led to changes in child behavior. If so, these changes may have been mediated by changes in maternal behavior that were not measured in the present research design.

In their previous experimental study, Belsky and his colleagues (1980) provided specific feedback to caregivers on their attention directing behavior. No other information was given to participants. This feedback led to specific changes in maternal attention directing behavior and to changes in infant exploratory play. While the current study also provided caregivers feedback on attention directing and other specific facilitory behaviors (and predicted a change in these behaviors), a great deal of other information was available to participants. Utilization of other information (such as what type of toys to use with a young child) by caregivers may have in turn impacted on child behavior, albeit through a different path than originally predicted.

This possibility is given support by the description feedback caregivers provided on group participation. Caregivers, regardless of group assignment, indicated that the opportunity for their children to interact with other children and the opportunity to interact with other parents were the most valued aspect of group participation. In 
addition, several parents indicated increased understanding of the importance of play in general. So while some parents noted that they gained specific information related to group assignment, this information was not considered to be the most advantageous or salient aspect of group participation by parents.

Although it may be plausible to ask whether participation in an eight week group focused on play can affect the quality of children's exploratory play regardless of the specific information provided to caregivers, that question can not be answered by the present study. Alternative hypotheses for the change in child behavior in the present study must also be considered. One possibility is that this change is the result of testing itself. Participants may have become accustomed to the setting that the videotaping occurred in or to the process of being videotaped. Another possibility is that maturational changes in the children led to a change in their exploratory play behavior. While possible, neither of these explanations fully accounts for the changes in quality of exploratory play when no change in quantity of exploratory play was demonstrated. Relationships Between Caregiver and Child Exploratory Play Behaviors Before and After the Intervention Period

Previous research (Fiese, 1990; Anzalone, 1994) has generally indicated that maternal behavior including expanding upon and supporting children's play, as well as following children's lead and re-directing attention to play is associated with more mature exploratory play. Maternal initiation and intrusiveness have been associated with less mature play. While these general rules have emerged across a number of studies, a number of exceptions have also emerged. The relationship of maternal behavior to the 
exploratory play behavior in infants with developmental delays is not yet clear (Hauser-Cram, 1996). Additionally, Anzalone (1994) suggests that relationship of maternal behavior to child behavior may change over time. In part, this study attempts to add to the literature available in these areas.

To an extent, the relationships between caregiver and child behavior in the present study follow the general rules regarding maternal behavior and child exploratory play. Prior to intervention, when children were engaged in play with their caregiver, support and expansion by caregiver was positively associated with quality and quantity of play. Patterns of expanding upon children's play were associated with increased sophistication (Group 1) and increased time spent in exploration (Group 2) even when children were playing independently. Additionally, a pattern of removal of toy by caregivers (an intrusive behavior) was related to a decrease in exploratory breadth in children playing alone (Group 1).

Interestingly, however, these relationships were not stable across time for either group. Subsequent to intervention, when playing together, caregiver social behavior (i.e., comments unrelated to child's play) was related to the amount of time children spent exploring and to behavioral tempo in the group that received general information on development. No significant relationships between caregiver behavior and child independent play were noted for this group at the conclusion of the intervention.

The relationship between maternal and child behavior was not stable for the participants in the exploratory play training group either. In fact, several caregiver variables generally considered to 
facilitate mature play were negatively related to measures that tap quantity of exploration post - intervention. In addition, the

caregiver behavior of initiating a play sequence, often considered to impede exploratory play, was in fact related to a decrease in the sophistication of play. However, Anzalone (1994) postulates that in some cases, maternal initiation could increase the novelty of the play situation and facilitate exploratory play.

Looking at the patterns of the relationships between maternal behavior and child exploratory play from the present study in conjunction with previous literature, two major conclusions can be drawn. The first is that these relationships are not stable over time. The maternal behaviors that facilitate exploratory play for an individual may change in relation to that child's developmental level. For example, younger children may profit from increased maternal structuring of the environment, while older children may respond to more control over the play interaction. Second, the patterns of behavior that facilitate exploratory play in atypically developing children may not be the same patterns found between typically developing children and their caregivers. In other words, facilitation of exploratory play may not be as straightforward as was suggested by previous research.

Exploratory Play Behavior In Developmentally Delayed Children

In previous studies (e.g., Jennings et al., 1979), cognitive development has been shown to be related to exploratory play. Additionally it has been shown that developmentally delayed children progress through Belsky and Most's play sequence more slowly than typically developing children (Krakow \& Kopp, 1982; 
1983). It has also been noted that the quality of delayed and non delayed children's play may differ (Krakow \& Kopp, 1982; 1983;

MacTurk et al., 1985). Many of these studies, while providing valuable information on exploratory play, have focused on relatively homogeneous populations (Hauser-Cram, 1996).

The present study contributes to the existing body of literature by expanding the definition of developmental delay to that used in practice by early intervention programs rather than focusing on a specific population of children with developmental disabilities (i.e., children with Down's Syndrome). Using a more heterogeneous sample, the results of the current study provide additional support for previous findings. In the present study developmentally delayed children, ranging in age from one to two years, were primarily using play behaviors that are typically associated with 9 to 14 month old children who do not have developmental delays (Belsky \& Most, 1981). Interestingly the mean developmental level of children in the study was 14 months. Additionally the range of the Average Developmental Level (a variable that assesses quality) for children in the current study is similar to the range of the Average Developmental Level for typically developing 9 month old children in a study conducted by Anzalone (1994). Thus in the present study, as in previous literature, the level and quality of exploratory play of developmentally delayed children differs from what is known about the exploratory play of children without developmental delays.

Maternal interaction patterns have long been considered a strong predictor of individual development (Hauser-Cram, 1996). Previous researchers have begun to delineate what maternal 
behaviors facilitate exploratory play in typically developing children (Anzalone, 1994). There is also a growing interest in the possibility that mothers with developmental delayed children differ from mothers of typically developing children during interactions focused on play. Mahoney (1988) indicated that mothers of children with delays are more directive. Blasco, Hrncir and Blasco (1990) found that quality of play in infants with cerebral palsy was related to the support mothers provided. In the present study the most frequently occurring maternal behaviors included expanding upon a child's play and introducing a new object to a child. Mothers rarely followed the lead of their children as demonstrated by the low incidence of caregivers imitating their children. The pattern of maternal behavior found across groups in this study appears to support Anzalone's contention that parents of children with disabilities may try to teach their children rather than "play" with them. It is of note that this pattern of maternal behavior persisted post intervention in the group that was encouraged to be more responsive to child cues and consequently less directive.

Overall there is a growing body of literature that suggests that the maternal behavior of mothers of children with developmental delays differs from that of mothers of children without delays. Moreover, these differences tend to be in the direction of being more directive. Current findings lend additional support to previous research in this area.

Conclusion

In summary, the purpose of this study was to determine if caregivers could be trained to facilitate the play of their 
developmentally delayed children. In addition, the relationships between caregiver behavior and child exploratory play pre- and post-intervention were examined. The present study also provided support for prior findings regarding exploratory play in developmentally delayed children.

Providing parents with training on strategies that are related to exploratory play competence in children did not lead to an increase in use of those strategies in the current study. However, children who participated in the study demonstrated increased quality of exploratory play at the conclusion of the study. Several hypotheses must be considered to account for this change. These include the possibility that group participation did affect change in parent and child behavior, although not along the predicted path. Other possibilities include the effects of testing or maturation. Given the importance ascribed to and the widespread use of parent training in early intervention programs, this study provides a valuable model of evaluating, rather than assuming the effectiveness of parent training programs.

Previous research has provided general guidelines about the types of maternal behavior that enhance or inhibit child exploratory play. Maternal behavior such as expanding upon and supporting children's play is associated with more mature exploratory play, while maternal initiation and intrusiveness has been associated with less mature play. The current study provides additional support for the growing body of evidence that these guidelines are, at best, just guidelines. The relationship between maternal behaviors and child exploratory play may not be stable across time. Changes in the 
relationship between maternal behavior and exploratory play may be associated with a child's developmental level as well as individual differences.

The present study also contributes to the existing body of literature on exploratory play by expanding the definition of developmental delay to that used in practice by early intervention programs rather than focusing on a specific population of children with developmental disabilities. Using a more heterogeneous sample, the results of the current study provide additional support for previous findings. That is the level and quality of exploratory play of developmentally delayed children differs from the exploratory play of children without developmental delays. Additionally the pattern of maternal behavior found across groups in this study appears to support Anzalone's contention that parents of children with disabilities may try to teach their children rather than "play" with them.

Limitations and Recommendations for Further Study

The conclusions of this study are limited by several factors. These factors include sample size as well as threats to internal and external validity.

First, : although this study attempted to consider ecological validity by holding groups in the early intervention center that parents were recruited from, the behavior of both parents and children may have been affected by coming to a potentially less familiar setting (than home) and interacting with unfamiliar adults and children. However, this situation does typically occur in early 
intervention programs, and thus results might be generalized to similar groups held at early intervention sites.

Second, the process of being videotaped might be considered to be a reactive procedure. This procedure may have differentially affected participants at the pre- and post- intervention videotaping sessions. Subsequent studies might decrease the effect of the novelty of videotaping by videotaping the mother and child over time, prior to the initiation of the intervention.

Third, the relatively small sample size limits the conclusions that can be drawn from the present study. Future studies might consider use of a larger sample so that statistical models such as factor analysis could be considered. Factor analysis would provide information on which, if any, caregiver variables provide cohesive subsets and on how those subsets change over time.

Fourth, an additional group to act as a control group would provide information on whether the changes in child exploratory play in the present study were simply the result of maturation or of play group participation. In future studies, participants in this proposed group could be videotaped during the same weeks as members of the exploratory play training group and the general information :group. However, they would receive no intervention or group participation in the intervening weeks.

While there are a number of studies that might potentially answer questions raised by the current investigation, the replication of this study with a no treatment control group may allow for further comment on the effectiveness of parent training in group interventions. Further research is this area is called for given the 
growing trend of providing early intervention services in group formats. Additionally a comparison of effectiveness of group training : to individual home based training on strategies to facilitate exploratory, play would further inform early intervention practice. 
Appendix A

Play Study Group Information

All Information is Confidential, (will only be discussed in group form) Name:

Address :

Phone Number:

Child's Name:

Age:

Date of Birth:

Martial Status (circle one): married single divorced separated

Mother's Education (circle one): less than 12 high school graduate

some college college graduate more than college

Father's Education (circle one): less than 12 high school graduate

$$
\begin{aligned}
& \text { some college college graduate } \\
& \text { more than college }
\end{aligned}
$$

Mother's Employment:

Father's Employment: 


\section{Infant Behavior Coding Sheet}

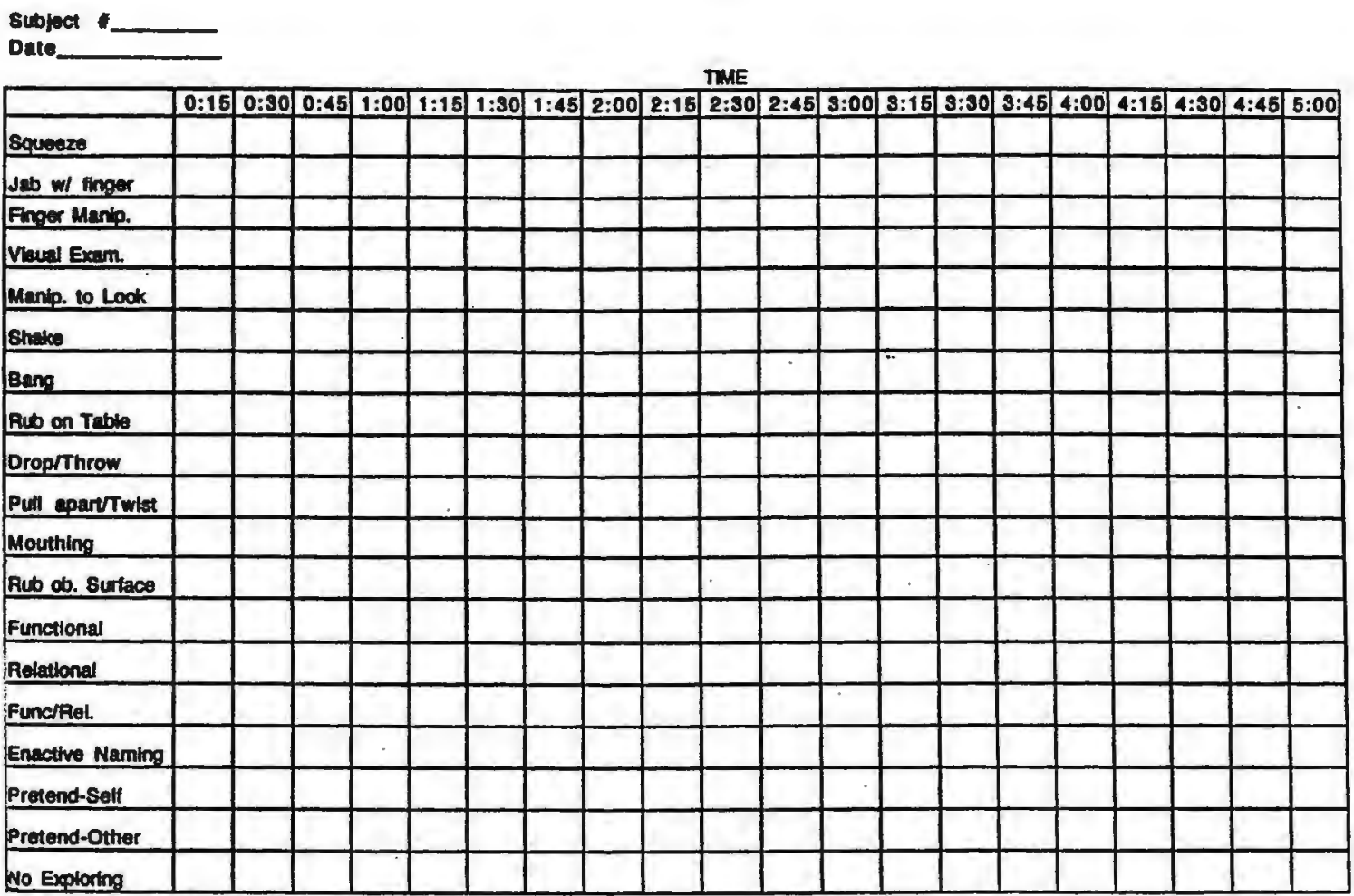


Caregiver Behavior Coding Sheet

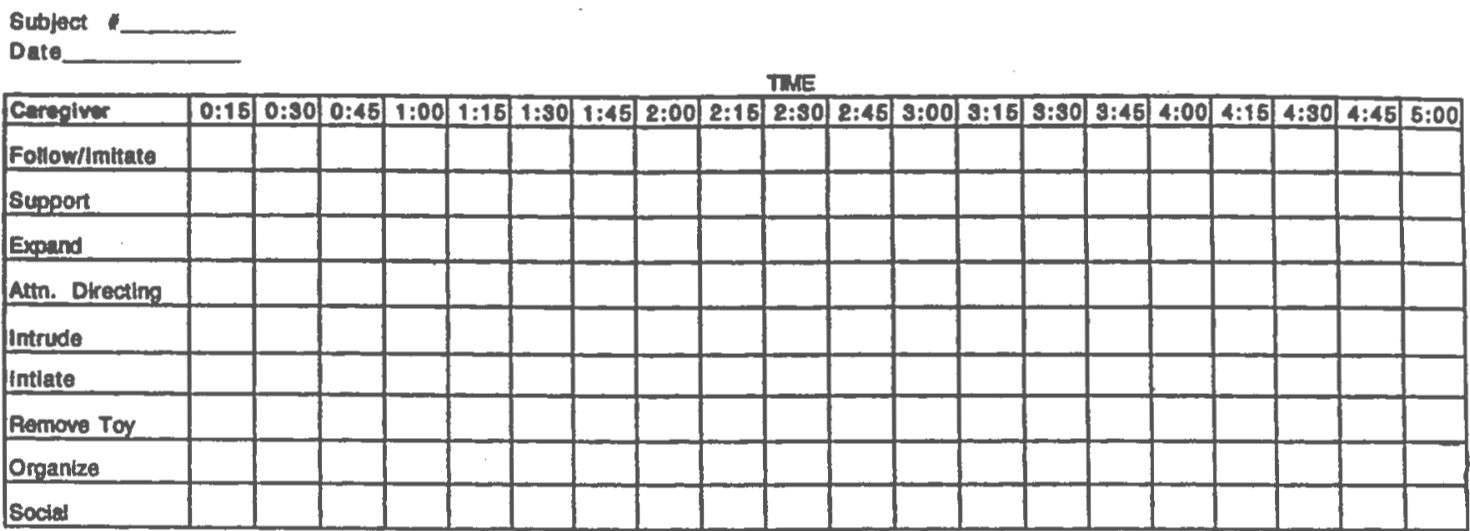


Introductory Letter

Dear Parent,

I am a certified school psychologist and a graduate student in the Psychology Department at the University of Rhode Island pursuing my Ph.D. in School Psychology. I work with Dr. David Caruso, a faculty member at the University, whose specialty is in the area of early childhood development. I would like to ask you and your child to participate in a study of play and of caregiver's involvement in play during early childhood.

While this is important research, your involvement and the involvement of your child is designed to be enjoyable. The project will involve eight weekly group play sessions. The children will be playing with toys both while you watch and while you join in. The toys that will be used have been designed especially for children who are the same age as your child. Additionally, throughout the course of eight sessions at your early intervention center, we will provide you will information about child development and children's play that will be useful to you at home. Participation is voluntary and contingent upon your consent. You will be free to withdraw from the study at anytime if you so wish. Your early intervention services will in no way be affected by your decision whether or not to participate in this study. 
Please let your Early Intervention service coordinator know if you are interested in learning more about this opportunity. I will then contact you by telephone and answer any questions you may have. I know that you join me in wanting a better understanding of how children play and of the role of caregivers in a child's play. I believe that this study will contribute to that goal. Thank you very much for considering to participate. If you have any questions, please call me at the Psychology Department at the University of Rhode Island (792-2193) or at home (423-3283).

Sincerely, Susan L. Curley, M.A.

Certified School Psychologist

David Caruso, Ph. D. Associate Professor 
The University of Rhode Island

Department of Psychology

Kingston, RI 02881-0808

Training Caregivers to Intervene in the Exploratory Play of Infants with Developmental Delays

\section{CONSENT FORM}

I have been asked to participate with my child in a study of play. The researcher will explain the project to me in detail. If I have more questions later, Susan Curley, the person mainly responsible for this study, will be happy to discuss them with me (423-3283).

I have been asked to take part in a study which will look at how caregivers of developmentally delayed infants might best help their children take advantage of play situations to practice and develop thinking skills.

If I decide to participate with my child, this is what will happen: my child and $I$ will participate in 8 ninety minute sessions at our regional early intervention center with up to 4 other caregivers and their children. During one session I will meet with the researcher and have the opportunity to discuss any questions I have. In another session a brief developmental evaluation (the Bayley Scales of Infant Development - 2nd edition) will be completed.

During the remaining sessions I will be asked to play with my infant or watch my infant play using a variety of safe and age appropriate 
toys, while the researcher provides me with information on play or early childhood development. Two sessions will be videotaped. At the conclusion of the sessions I may be asked my opinion regarding the usefulness of the information given, and if I noted any changes in my behavior or that of my infant due to the sessions.

There are no known risks involved in this study. A direct benefit to me for taking part in this study is that I will gain useful information about children's development. Also, the researcher may learn more about the play of developmental delayed infants and the role that caregivers may have in helping their children develop play skills. This information may eventually help other caregivers of developmentally delayed infants.

My part in this study is confidential. No information will identify me or my child by name. In all records my child and I will be identified by a number. Only the researcher will have access to the number code and corresponding names. Videotapes will remain in the possession of the investigator and may be used for further study. Information obtained will be used only in scholarly publications and presentations and I and my child will be in no way identifiable.

If this research project causes me or my child any injury, I should write or call the office of the University of Rhode Island's Vice Provost for Research, 70 Lower College Road, University of Rhode Island, Kingston 02881(792-2635).

The decision whether or not to take part in this study is up to me. I do not have to participate. Nonetheless, if I decide to participate, my infant and I may quit at any time. Whatever I decide 
will have no consequences for the services I receive through my early intervention center. If I wish to stop participation, I simply - inform Susan Curley (423-3283) of that decision.

If I have any questions about the purpose or manner in which this project is conducted, I may discuss my concerns with Susan Curley (792-4291) or with Dr. David Caruso (792-5960), anonymously if I chose. In addition I may contact the office of the University of Rhode Island's Vice Provost for Research, 70 Lower College Road, University of Rhode Island, Kingston 02881(792-2635).

I have read the Consent Form. My questions have been answered. My signature on this form means the I understand the information and agree to participate in this study with my infant. 


\section{Standardized Instructions}

- Instructions for Caregivers:

Introduction

Researcher: For the next ten minutes or so, you and your baby will be playing with some toys. We'll do this in three different segments.

Segment 1

Researcher: First we'll let play with a "warm-up" toy for a few minutes, until s/he is in a relaxed and playful mood.

Segment 2

Researcher: At the end of the warm-up period I will give a set of toys. During the first five minutes I want you to just watch. Please respond normally if____ tries to get your attention but do not start to play with the toys or your baby.

Segment 3

Researcher: I will signal you when the next five minute period begins. In this segment I would like you to play with your baby and the toys as you typically might at home.

\section{At conclusion}

That was great! Thank you for your help. 
Appendix G

Standardized Set of Toys

- The following toys were available to children and caregivers during pre- and post-test videotaping sessions:

1. One inch sponge block

2. One inch Styrofoam block

3. One inch wood block

4. Metal bell with handle

5. Plastic phone rattle with movable dial

6. Small stuffed animal (duckie)

7. Plastic rattle

8. Doll's hairbrush

9. Plastic toy teacup

10. Wooden clothespin

11. Infant sized spoon

12. Small toy car

13. Small baby doll

14. Toy baby bottle 
Appendix $\mathrm{H}$

Overview of the Eight Weekly Sessions for the Comparison Groups

\begin{tabular}{|c|c|c|}
\hline Week & $\begin{aligned} & \text { Exploratory } \text { Play } \\
& \text { Group } 1 \\
&\end{aligned}$ & $\begin{array}{c}\text { General Information } \\
\text { Group } 2\end{array}$ \\
\hline 1 & $\begin{array}{l}\text { Overview, introduction, } \\
\text { Consent Forms signed, } \\
\text { free play with } \\
\text { appropriate toys }\end{array}$ & $\begin{array}{l}\text { Overview, introduction, } \\
\text { Consent Forms signed, } \\
\text { free play with } \\
\text { appropriate toys }\end{array}$ \\
\hline 2 & $\begin{array}{l}\text { Individual appointments } \\
\text { to complete BSID-II }\end{array}$ & $\begin{array}{l}\text { Individual appointments } \\
\text { to complete BSID-II }\end{array}$ \\
\hline 3 & $\begin{array}{l}\text { Pre-intervention } \\
\text { videotaping, independent } \\
\text { play for the remainder } \\
\text { of the session }\end{array}$ & $\begin{array}{l}\text { Pre-intervention } \\
\text { videotaping, independent } \\
\text { play for the remainder } \\
\text { of the session }\end{array}$ \\
\hline 4 & $\begin{array}{l}\text { Information on observing } \\
\text { cues ( } 20 \text { minutes), } \\
\text { feedback provided to } \\
\text { parents on facilitating } \\
\text { exploratory play during } \\
\text { free play ( } 30 \text { minutes), } \\
\text { review and ideas for home } \\
\text { activities ( } 10 \text { minutes) }\end{array}$ & $\begin{array}{l}\text { Information on motor } \\
\text { development ( } 20 \text { minutes), } \\
\text { feedback provided to } \\
\text { parents on facilitating } \\
\text { motor development during } \\
\text { free play ( } 30 \text { minutes), } \\
\text { review and ideas for home } \\
\text { activities ( } 10 \text { minutes) }\end{array}$ \\
\hline 5 & $\begin{array}{l}\text { Information on attention } \\
\text { directing ( } 20 \text { minutes), } \\
\text { feedback provided to } \\
\text { parents on facilitating } \\
\text { exploratory play during } \\
\text { free play ( } 30 \text { minutes), } \\
\text { review and ideas for home } \\
\text { activities ( } 10 \text { minutes) }\end{array}$ & $\begin{array}{l}\text { Information on cognitive } \\
\text { development ( } 20 \text { minutes), } \\
\text { feedback provided to } \\
\text { parents on facilitating } \\
\text { cognitive development } \\
\text { during free play } \\
\text { ( } 30 \text { minutes), } \\
\text { review and ideas for home } \\
\text { activities ( } 10 \text { minutes) }\end{array}$ \\
\hline 6 & $\begin{array}{l}\text { Information on imitation, } \\
\text { and support ( } 20 \text { minutes), } \\
\text { feedback provided to } \\
\text { parents on facilitating } \\
\text { exploratory play during }\end{array}$ & $\begin{array}{l}\text { Information on language } \\
\text { development ( } 20 \text { minutes), } \\
\text { feedback provided to } \\
\text { parents on facilitating } \\
\text { language development }\end{array}$ \\
\hline
\end{tabular}


free play (30 minutes), review and ideas for home activities (10 minutes) during free play

(30 minutes), review and ideas for home activities (10 minutes)

7

Information on expanding

Information on social play (20 minutes), feedback provided to parents on facilitating exploratory play during free play (30 minutes), review and ideas for home activities (10 minutes)

8

Post-intervention videotaping, independent play for the remainder of the session development (20 minutes), feedback provided to parents on facilitating social development during free play (30 minutes), review and ideas for home activities (10 minutes)

Post-intervention videotaping, independent play for the remainder of the session 
Appendix I

Group Activity Plans

\section{WEEK 1}

\section{FOR BOTH GROUPS}

\section{Set-up:}

5 toys (to occupy infants during discussion) set up in a circle, backup toys close but out of infants sight

\section{Additional materials:}

Sign-up sheets for following week

Refreshments/ snack

\section{Introduction:}

I have had a chance to talk to each of you individually on the phone, but its nice to meet you in person. I'd like to take a few minutes to get to know each other, so first let's introduce ourselves and our children to the other members of the group (warm-up activity - tell a humorous story about something that has occurred since your child's birth?).Then I'll talk a bit about what we'll be doing over the next few weeks. After that, we'll talk about why kids need to play.

Review:

Review 8 week sequence

Describe format of sessions

Discuss confidentiality within group

Discuss need to feel comfortable - i.e. feel free to leave room if need to or ask any questions

Discussion:

Any ideas why kids play? 
Based on responses raise the following; 1) kids are exploring how things work and learn about world around them, 2) have the chance to be in control for a change (helping to develop independence) 3) practice communication skills (eye contact, gesturing, facial expressions, early expressive language, etc.) 4) when playing with parent develop social skills (i.e. turn taking)

5) use and develop motor skills (coordination, strength)

What are some of the things your child enjoys?

Use responses as examples for the a 5 points raised above Questions

Conclusion:

Brief summary of discussion

Sign people up for times the following week 


\section{FOR BOTH GROUPS}

\section{Set-up:}

Bayley/protocol

small table

infant seat

Additional materials:

none

\section{Introduction:}

Today I'll be working with alone to get an idea of how he/she uses his/her thinking skills. You might have seen ___ do similar types of things at EI before. Remember you can't help__, we need to see how d__ does alone. But if you have seen do similar things at home let me know and please feel free to ask any questions. This should take about $1 / 2$ hour or so.

\section{Conclusion:}

Do you have any questions? Remember, next week we'll meet with the group at our regular time (state when group meets) 


\section{WEEK 3}

\section{FOR BOTH GROUPS}

\section{Set-up:}

-5 toys (to occupy infants during discussion) set up in a circle, -backup toys close but out of infants sight

-small table/infant seat

-5 play stations (construction materials, manipulatives, pretend/house materials, etc.)

-video camera/tape

\section{Additional materials:}

-standardized toy set

-standardized instructions

-Refreshments/ snack

\section{Introduction:}

Today we are going to practice how the group is going to go. We are going to videotape both to make sure that everything goes smoothly and to see what kinds of play are being used now. Basically each infant will have a turn at each of the play stations around the room including the one where the video camera is. Each turn will last about ten minutes - I'll tell you when it's time to switch play stations. If you feel that your child is getting bored with the toys at the play station you are at, feel free to take a new toy from the counter. I'll be running the video camera so I'll get the chance to talk a bit to each of you during the recording and I'll give you the specifics on the videotaping when you get to that. Any questions? 
Conclusion:

Basically we practiced how we are going to run the group from now on. The only things that will be different is that we won't videotape every week so I won't be stuck behind the camera. I'll be able to move around the room to different play stations to play with you and answer questions. Does anyone have any ideas that make how we run the group better. based on how things went today? 


\section{WEEK 4}

\section{FOR THE GENERAL INFORMATION GROUP}

\section{Set-up:}

-5 toys (to occupy infants during discussion) set up in a circle, -backup toys close but out of infants sight

-5 play stations (construction materials, manipulatives, pretend/house materials, gross motor toys: i.e. slide, balls, riders) Additional materials:

-standardized activity plan

-Refreshments/ snack

\section{Introduction:}

Today we'll discuss how play helps kids develop physically. Physical development can be divided into two areas - gross motor development and fine motor development.

Gross motor development is the development of large muscles and how to use them. Some examples of large muscles would be the muscles in the legs and the arms. Can anyone think of ways that play might help this type of development? How about things in this room that might help develop gross motor skills? (Discuss answers, be sure to include crawling, leads to walking, leads to running, also kicking/throwing balls, riders, slides, swings etc.). helps kids gain gross motor skills by

Any

other ideas? If you have questions about gross motor development you could talk to a physical therapist.

Fine motor skills is the development of the small muscle and how we use them. Usually when we talk about fine motor skills we are talking about the skill with which we use our hands. This can 
also include our we coordinate the action of our hands and eyes together. Maybe the easiest way to see this type of development in young children is to look at how they pick up something they want. . At first, they may not even be very good at touching a toy but eventually they will be able use a rough grasp (demonstrate), that grasp becomes better and better developed until it is much cleaner and they can even start to pick up and hold more then one thing at once. As a child gains more control over his/her hands, s/he will also start to gain control over their fingers, like when they pick up a Cheerio (demonstrate). Can anyone think of ways that play might help this type of development? How about things in this room that might help develop fine motor skills? (Discuss answers, be sure to include blocks, puzzles, painting, sorting). If you have questions about your child's fine motor skills, you could ask an occupational therapist.

\section{Conclusion:}

Basically we talked about two different kinds of physical development - gross and fine motor. Did anyone see their child use these types of skills in play today? (If not, I will give some examples that I noted). What are some things that we can do to help our children's physical development at home? Lots of the time the things you do with your kids outside contribute to gross motor skill, like going to the park, playing ball in the yard. Kids also develop gross motor skills in the house - especially when they are young. Things you can do inside to help develop gross motor skills would be to roll a ball back and forth, let them practice getting around the house, 
maybe ride a little scooter around and when they're old enough help them work on getting up and down stairs.

You can use things, like puzzles, blocks, crayons/markers at home to promote fine motor skills. Other things that you might do at home to promote these skills would include letting them play around with putting things in containers and dumping them out again or (if your head can stand it) occasionally let them bang on things like pots and pans. If your outside, playing in the sandbox is a way to help fine motor skills get better. 


\section{FOR THE EXPLORATORY PLAY TRAINING GROUP}

Set-up:

-5 toys (to occupy infants during discussion) set up in a circle, -backup toys close but out of infants sight

-5 play stations (construction materials, manipulatives, pretend/house materials, gross motor toys: i.e. slide, balls, riders) Additional materials:

-standardized activity plan

-Refreshments/ snack

\section{Introduction:}

Today I want us to really pay attention to what our kids are doing. I don't mean just watching them to make you they don't get hurt because you all already to that. Instead I want you to watch them play as if you had never seen them, or any other kid, play. These are the types of questions I want you to ask as you watch them. What types of things are they doing? Do they go to the same types of toys again and again or not? Do they do a wide variety of things with the toys they choose or do they tend to do the same type of things? When playing, about how long do they stay with one toy before they put it down? How long do they play by themselves before they lose interest? How do they show you that they are bored/ done with a toy? Are they interested in other kids yet? what do they do with other kids? Do they like it when you actually play with them? What do they like to play with you? Are there times, that they look to you for help? What do they do if you pretend like you don't notice? Are there times that they clearly don't want your help? So basically 
today I want to encourage you to really look closely at the patterns of play that your child has. I know you already have some ideas about this (examples from what kids have shown in previous groups), but I want us to be able to watch and understand our children play at a closer level, so we will get a greater understanding of when and how we can help their play skills grow. At the end of the play group, we'll talk about what we noticed.

Conclusion

What types of things did you notice as you watch your child play today? Did you notice things you haven't seen before? Particularly, how did you pick up when the kids weren't interested in what they were doing? How did you respond? Over the next week at home, I'd really like you to continue to practice watching your kids as they play, so that you can gain a deeper understanding of the patterns they show. 


\section{WEEK 5}

\section{FOR THE GENERAL INFORMATION GROUP}

\section{Set-up:}

-5 toys (to occupy infants during discussion) set up in a circle, -backup toys close but out of infants sight

-5 play stations (construction materials, manipulatives: sorting toys, puzzles, pretend/house materials, art materials, gross motor toys: i.e. slide, balls, riders)

Additional materials:

-standardized activity plan

-Refreshments/ snack

\section{Introduction:}

Today we'll discuss how play is related to cognitive development. Cognitive development is the development of thinking and problem solving skills. It is related to learning and learning how to get by the world (adaptation). Basically in young children these thinking skills are divided into two areas. One area is how the child uses thinking skills to gain information about the world. The other area is seen as infants learn to influence their world - they learn to control both people and things within their world. You can watch children learning about controlling things during play. An example is when a child learns to press a button on a toy to make music. Can you think of other ways that shows you $s /$ he is learning about the environment? (If no examples given, I'll give one based on previous observation- i.e. moving to rock rowboat). What about ways that uses to influences you? (Discuss examples, include crying, smiling and responses) 
One of the ways to help infants to learn about the world is to provide them with new opportunities to learn about things. How can we provide these opportunities??(Discuss answers, include providing new experiences: going places like to group, to the park, over a friends house, providing different types of toys). Can anyone think of ways that play might help this type of development? (Discuss answers, be sure to include blocks, puzzles, painting, sorting). Play provides children with the opportunity to learning about the world. Often that is what children are doing when the mouth things, bang things, use objects together and pretend with objects.

We also want to provide children with the opportunity to control or influence things. This can be done with toys that produce a response to an infants actions (i.e.. rattle: infant shakes it makes a noise) What are some other toys in this room that can control? (discuss answers, include music toys and pop up toys). Often to get a toy to make a respond, a child might have to try out different ideas. as they practice different ideas, they are beginning to use problem solving (example for observation). You can also play games with your children so that when they do something, you respond (i.e. they touch your nose and you go beep). In order for to learn from this type of game, your response must happen every time soon after your child starts the game. After all toys don't respond sometimes.

Another good game to play is the labeling game. In this game a parent says the name of an object. The child starts to link what the parent is saying to the object. As this happens the game can get more complex, as the parent can begin to make requests using the 
object like get me the Hide the this helps the child use his/her memory and follow directions. Are their any games that you play with (discuss responses). If you have questions about your child's cognitive skills, you could ask a teacher or psychologist.

\section{Conclusion:}

Basically we talked about the development of two different kinds of cognitive or thinking skills. These skills include how a child get information about the world and how a child influences the world around him/herself. Did anyone see their child use these types of skills in play today? (If not, I will give some examples that I noted). What are some things that we can do to help our children's cognitive development at home? Lots of the time the games you play with your children (like the labeling game, peek a boo etc.) are important for this type of development. It is also important to let kids explore, so let them crumple up an old piece of paper, pour water from cups in the tub etc. Let your children explore what they are interested in as long as its safe. Good toys to get are ones that children can control or manipulate to get a response. It is also nice to get toys that grow with children. Blocks are a good example of this type of toy. Kids can start by banging blocks, then work on knocking over your tower, then on building their own tower, then onto building amazing buildings. - Others include nesting containers, balls, toy dolls and phones to encourage pretend play.

Sources: McCall, R. B. Infants: The New Knowledge 


\section{FOR THE EXPLORATORY PLAY TRAINING GROUP}

\section{Set-up:}

-5 toys (to occupy infants during discussion) set up in a circle, -backup toys close but out of infants sight

-5 play stations (construction materials, manipulatives, pretend/house materials, gross motor toys: i.e. slide, balls, riders Additional materials:

-standardized activity plan

-Refreshments/ snack

\section{Introduction:}

Last week we talked about the importance of watching our children closely in order to learn about how they play and how they learn through play. Remember I asked you to pay attention to the types of things your child does while playing - what s/he likes, what s/he doesn't like, what s/he does when unsure of what to do next I also asked you to pay attention to what your child does when s/he is done playing with a particular toy or is done playing a certain game. What types of things did you notice while watching your child through the week? (Discuss answers, if needed use examples from previous groups, i.e. tossing toys away, attempting to leave play area, looking toward mother, being "unoccupied" to demonstrate to mothers how an unengaged child may appear. Once caregivers appear to have a firm understanding of what their child looks like when unengaged, begin discussing strategies that parents can use to reengage their child.) 
Suppose you notice that is not playing, $s /$ he is not engaged with the environment and isn't engaged with another person, what do you do? (Discuss answers) One of the things that is important to do is to wait a second or two and see if is just taking a break, if so after a little while s/he'll start playing again by his/herself. If within a second or two doesn't start playing again, S/he might be stuck, unsure of what to next. When your child gets stuck like this, you will play an important role in getting him/her unstuck. One way to do this is to redirect your child to play using verbal or physical signals. These signals could include saying your child's name, talking about what they were playing with, pointing towards the toys, picking up toys and showing them and what they do to your child. It can also be a combination of these things. Can you think of which of these strategies you use now to engage your child in play? What other techniques do you use? Today while we're playing I'd like you to watch closely, note when they seem to have lost interest in what they are playing, wait a second to see if they start playing again, and if not, use a couple of the techniques we talked about.

\section{Conclusion}

What did you notice as you watched your child play today? Did you notice when appeared to lose interest in what they were doing? If so, what did you do? (Discuss answers). Did the strategies you used work? Describe what happened (Discuss answers, provide examples from my observation of interactions)

Over the next week at home, I'd really like you to continue to practice watching your kids as they play, so that you see when they 
are not attending to their environment, and use the techniques that we talked about today to reengage them in the environment so that they can learn from it. 
WEEK 6

FOR THE GENERAL INFORMATION GROUP

Set-up:

-5 toys (to occupy infants during discussion) set up in a circle,

-backup toys close but out of infants sight

-5 play stations (construction materials, manipulatives: sorting toys, puzzles, pretend/house materials, art materials, gross motor toys: i.e. slide, balls, riders)

Additional materials:

-standardized activity plan

-Refreshments/ snack

\section{Introduction:}

Today we'll discuss how play is related to language development. Language development is the development of communication skillsunderstanding others and getting others to understand you. Basically in young children communication skills are divided into two areas. One area, receptive language, is what a child understands. The other area, expressive language is what a child is able to say or express. Usually children understand alot more than they can actually say. The roots of language are found early in a child's life, when they coo and babble as well as when they look at you when you talk to them. Early on you can encourage a child's language development by playing imitation games. This is like when a child makes a sound, you make the same sound back or when you try to get a child to imitate you. These games start to give a child practice taking turns and give him/her the idea that making sounds is important. We also help children learn language when we help them 
make connections between words and objects. A great way to do that is to label things, including labeling things during play. Do you do that at all now? (Discuss answers, include discussion on verb, preposition labeling as well as nouns). During play you can set up the situation to include opportunities to use new words. For example you can use a bucket and another smaller toy to practice in, on, under etc. What other words might come up in play (Discuss answers). During play you also have the opportunity to respond to your child's attempts to communicate with you. For example, if they point to an object, making a noise, you can tell them what the object is and help them get it. This helps a child understand that language can help that child get what they want. In other words, language is another way to influence the world, which we know is important to children. As a child's language skills development it's best to talk at the child's level or slightly above it. So for example, when your child is pretty good at saying one word, start to demonstrate how to put two words together. What are other ways that you can help with language development (Discuss). If you have questions about your child's language development, you can talk to a speech/language therapist.

\section{Conclusion:}

Today we talked about the development of two different kinds of language skills. These skills include how a child learns to understand language and how a child learns to express him/herself. Did anyone see their child use these types of skills in play today? (If not, I will give some examples that $I$ noted). What are some things that we can do to help our children's language development at home? 
(Discuss).Lots of the time the games you play with your children (like the labeling game, peek a boo etc.) are important for this type of development, like they are for cognitive development. Also it is important to remember to respond to your child's attempts to communicate with you. You can really do this throughout the day at home. It is especially nice to take some time to play with your infant and practice language skills, because the you will be working on words/objects and skills your child is interested in and motivated to learn

Sources: McCall, R. B. Infants: The New Knowledge White, B. L. The First Three Years of Life 
FOR THE EXPLORATORY PLAY TRAINING GROUP

Set-up:

-5 toys (to occupy infants during discussion) set up in a circle, -backup toys close but out of infants sight

-5 play stations (construction materials, manipulatives: sorting toys, puzzles, pretend/house materials, art materials, gross motor toys: i.e. slide, balls, riders)

Additional materials:

-standardized activity plan

-Refreshments/ snack

\section{Introduction:}

We have talked about watching your child closely while s/he plays and about how to get your child's attention back to play. The next step is to build upon what a child is already doing to teach them new things. This involves watching_____osely to see what s/he is doing, imitating, praising \& describing that, then adding to it. For example you might notice______ banging a block against the table. You could say "look at you banging that block" and start banging the block yourself. Why might is be helpful? (Raise the point that it maintains interaction) When appears to have lost interest in the block, redirect his/her attention to the block physically/verbally and show him/her something new like banging two blocks together, or putting the blocks in a cup. Generally you want to make little steps when showing your child something new. Don't expect to go from banging the block on the table to creating a tower. Remember little steps!! Also, it's important to 
remember to praise for trying new things, even if s/he isn't perfect at first. This will give the motivation to keep working on what you are trying to teach him/her. Another helpful hint to think about is the importance of positioning your child so s/he can play with materials or engage in social interaction. If a child can't reach the table, what can you do? (Discuss) Or what if a child is trying to build a block tower on a blanket? Can you change the child's position to help them obtain success? Try to use clear directions, and remember to give a chance to practice. Don't get discourage if a child doesn't do what you showed him/her right away. Wait a couple of seconds and try again, if still isn't interested that's OK, just watch what $s / h e$ is doing and start the process over again!!

\section{Conclusion:}

Today we talked about imitating what your child is doing, expanding upon their activities, supporting their efforts and re-engaging them in play. What happened when you tried to use these ideas? How did your child respond to praise? Did the issue of support/positioning come up? What did you do? Did you notice any changes in the way your child played?(Discuss, If no discussion, I will give some examples that I noted). What are some things that we can do to use these ideas at home? (Discuss).Lots of the time the games you play with your children are important for development.. You can really play with your child throughout the day at home. It is especially nice to take some time to play with your child and practice these skills, because the you will be working on things and skills your child 
is interested in and motivated to learn. Over the next week, practice imitating, supporting and praising your child at home. 


\section{WEEK 7}

\section{FOR THE GENERAL INFORMATION GROUP}

\section{Set-up:}

-5 toys (to occupy infants during discussion) set up in a circle,

-backup toys close but out of infants sight

-5 play stations (construction materials, manipulatives: sorting toys, puzzles, pretend/house materials, art materials, gross motor toys: i.e. slide, balls, riders)

\section{Additional materials:}

-standardized activity plan

-Refreshments/ snack

\section{Introduction:}

Today we'll discuss how play is related to social development. Social development is the development of the skills needed to interact with other people - both adults and other children. Play is important to social development because it provides a safe environment for a child to explore social relationships. We can see this in group. Remember when (Give example from group, i.e. one child kissing, hitting, watching or sharing with another). play is also important because it allows children to practice skills that they will need later, including social skills. For example, when a child plays with a baby doll, s/he is practicing how to care for a real baby. Early social interactions between infants and adults or other children often include watching each other. Often however an infant might feel safer playing with toys instead of another infant since toys are more predictable. Later infants will start to interact over a toy. At first this interaction might just be to fight over the toy but in time and 
with parent encouragement children begin to take turns and eventually play together. Playing together can begin with imitation games, such as Peek a boo, or each child taking a turn with a toy a giving the other child a chance to imitate them. Parents of course can help a child learn the skills s/he needs for social interaction through play by playing with their children. In play parents can practice turn taking and imitation with their child. Parents can also encourage the development of a child's social skills by providing them the opportunity to play with other children. Additionally, it is important to think about what kind of toys promote interaction between children. Generally bigger toys like slides/climber give children more opportunity for social interaction than do small toys like puzzles. Toys like balls encourage turn taking

\section{Conclusion:}

Today we talked about the development of social skills. These skills include how a child learns to interact with other people. Did anyone see their child use these types of skills in play today? (If not, I will give some examples that I noted). What are some things that we can do to help our children's social development at home? (Discuss).Lots of the time the games you play with your children (like the peek a boo etc.) are important for this type of development, like they are for cognitive and speech development. Also it is important to remember to respond to your child's attempts to be social with you. You can really do this throughout the day at home. It is especially nice to take some time to play with your infant and practice social skills, because the you will be working when your child is interested 
in and motivated to interact with you. If you have questions about social development, you could talk to a psychologist or educator 


\section{WEEK 7}

\section{FOR THE EXPLORATORY PLAY TRAINING GROUP}

\section{Set-up:}

-5 toys (to occupy infants during discussion) set up in a circle, -backup toys close but out of infants sight

-5 play stations (construction materials, manipulatives, pretend/house materials, gross motor toys: i.e. slide, balls, riders Additional materials:

-standardized activity plan

-Refreshments/ snack

\section{Introduction:}

Last week we talked about the importance of positioning your child so s/he can play with materials or engage in social interaction. We also talked about describing your child's actions as they play, praising them for attempting new things and imitating what your child does. Did you try these things at home? What happened? (Discuss) If you are comfortable with doing these different things and do them frequently, its time for the next step. The next step is to build upon what your child is already doing to teach them new things. This involves watching___ closely to see what $s / h e$ is doing, imitating, praising \& describing that, then adding to it. For example you might notice banging a block against the table. you could say look at you banging that block and start banging the block yourself. When appears to have lost interest in the block, redirect his/her attention to the block physically/verbally and show Him/her something new like banging two blocks together, or putting the blocks in a cup. Generally you want to make little steps 
when showing your child something new. Don't expect to go from banging the block on the table to creating a tower. Remember little steps!! Also, its important to remember to praise for trying new things, even if s/he isn't perfect at first. This will give__ the motivation to keep working on what you are trying to teach him/her. Other helpful hints to follow when you are showing your child something new include: Describe in a couple of ways what you are doing as you show how to do something, Try to use clear directions, and remember to give a chance to practice. Don't get discourage if you child doesn't do what you showed him/her right away. Wait a couple of seconds and try again, if still isn't interested that's $O K$, just watch what $s /$ he is doing and start the process over again Conclusion

What did you notice as you tried showing your child how to do new things today? (Discuss answers). Did the strategies you used work? Describe what happened (Discuss answers, provide examples from my observation of interactions)

Over the next week at home, its important to continue to use praise, imitation, description. positioning. See if you can practice showing how to do something new. Remember to demonstrate and describe what you are doing, take little steps and use praise. It essential that you watch what is doing and try to build on that 


\section{WEEK 8}

\section{FOR BOTH GROUPS}

Set-up:

-5 toys (to occupy infants during discussion) set up in a circle, -backup toys close but out of infants sight

-small table/infant seat

-5 play stations (construction materials, manipulatives, pretend/house materials, etc.)

-video camera/tape

Additional materials:

-standardized toy set

-standardized instructions

-Refreshments/ snack???

\section{Introduction:}

Today is our last group. We are going to videotape to see what kinds of play the children are using now. Like the last time we taped, each infant will have a turn at each of the play stations around the room including the one where the video camera is. Each turn will last about ten minutes - I'll tell you when it's time to switch play stations. If you feel that your child is getting bored with the toys at the play station you are at, feel free to take a new toy from the counter. I'll be running the video camera so I'll get the chance to talk a bit to each of you during the recording and I'll give you the specifics on the videotaping when you get to that. Any questions?

\section{Conclusion:}

Basically, we are done with our play group. I'd like to thank you for participating. You all really helped me out. Are their any questions 
about the group that I can answer for you? Does anyone have any ideas that make how we run the group better for other parents and children that we be participating in future groups? If any of you are interested in the types of things I do in other groups, let me know I'd be happy to fill you in. If you don't mind I have a brief questionnaire I'd like you to fill out to make the group better for others. (Pass out questionnaire). your answers will be anonymous unless you decide to fill in your name, so I can call you if I have any questions. 
Appendix $\mathbf{J}$

Parent Feedback Sheet

Overall did you find the group helpful? Why or why not?

What did you learn from the group?

What was your favorite part of group?

What part of group did you like least?

What would you like to change about the group for next time?

Can I call you if I have questions about your answers? If yes, please write down your name 
Appendix K

Analysis of Variance for the Effect of Time on Children's Behavior

During Independent Play

$\begin{array}{lllll}\text { Source } & \text { Mean Difference } & \underline{\mathrm{df}} & \underline{\mathrm{F}}\end{array}$

\begin{tabular}{|c|c|c|c|c|c|}
\hline Behavioral & Gr 1 & 0.3 & 1,52 & 2.54 & 2.57 \\
\hline Tempo & Gr2 & 0.5 & & & \\
\hline Exploration & Gr 1 & 3.3 & 1,52 & 440.72 & 1.35 \\
\hline Time(\%) & Gr2 & 8.2 & & & \\
\hline Total & Gr 1 & 5.9 & 1,52 & 1989.97 & 3.67 \\
\hline Exploring & Gr2 & 15.6 & & & \\
\hline Total & Gr 1 & 2.7 & 1,52 & 58.63 & $17.7 *$ \\
\hline Breadth & Gr2 & 1.3 & & & \\
\hline Caruso & Gr 1 & 1.8 & 1,52 & 33.03 & $17.6 *$ \\
\hline Breadth & Gr2 & 1.1 & & & \\
\hline Spontaneous & Gr1 & 0.9 & 1,52 & 5.14 & $4.49 *$ \\
\hline Mastery Score & Gr2 & 0.3 & & & \\
\hline Average & Gr 1 & 0.4 & 1,52 & 1.01 & $4.31 *$ \\
\hline $\begin{array}{l}\text { Developmental } \\
\text { Level }\end{array}$ & Gr2 & 0.2 & & & \\
\hline
\end{tabular}

${ }^{*} \mathrm{p}<.05$ 
Appendix L

Analysis of Variance for the Effect of Time on Children's Behavior

During Play with Caregiver

Source

Mean Difference

df

$\underline{\mathrm{MS}}$

F

\begin{tabular}{|c|c|c|c|c|c|}
\hline Behavioral & Gr 1 & 0.3 & 1,52 & 0.35 & 0.33 \\
\hline Tempo & Gr2 & 0.0 & & & \\
\hline Exploration & Gr 1 & 6.7 & 1,52 & 2493.63 & $4.70 *$ \\
\hline Time(\%) & Gr2 & 20.0 & & & \\
\hline Total & Gr 1 & 5.3 & 1,52 & 1192.36 & 1.84 \\
\hline Exploring & Gr2 & 13.1 & & & \\
\hline Total & Gr 1 & 2.2 & 1,52 & 77.03 & $9.71 *$ \\
\hline Breadth & Gr2 & 1.6 & & & \\
\hline Caruso & Gr 1 & 1.3 & 1,52 & 41.32 & $6.94 *$ \\
\hline Breadth & Gr2 & 1.5 & & & \\
\hline Spontaneous & Gr1 & 0.6 & 1,52 & 3.58 & 2.83 \\
\hline Mastery Score & Gr2 & 0.4 & & & \\
\hline Average & Gr 1 & 0.1 & 1,52 & 0.187 & 0.26 \\
\hline $\begin{array}{l}\text { Developmental } \\
\text { Level }\end{array}$ & Gr2 & 0.1 & & & \\
\hline
\end{tabular}

${ }^{*} \mathrm{p}<.05$ 
Graphs of the Means of Variables Significantly Effected by the Factor Time

Figure 1.

Independent Play

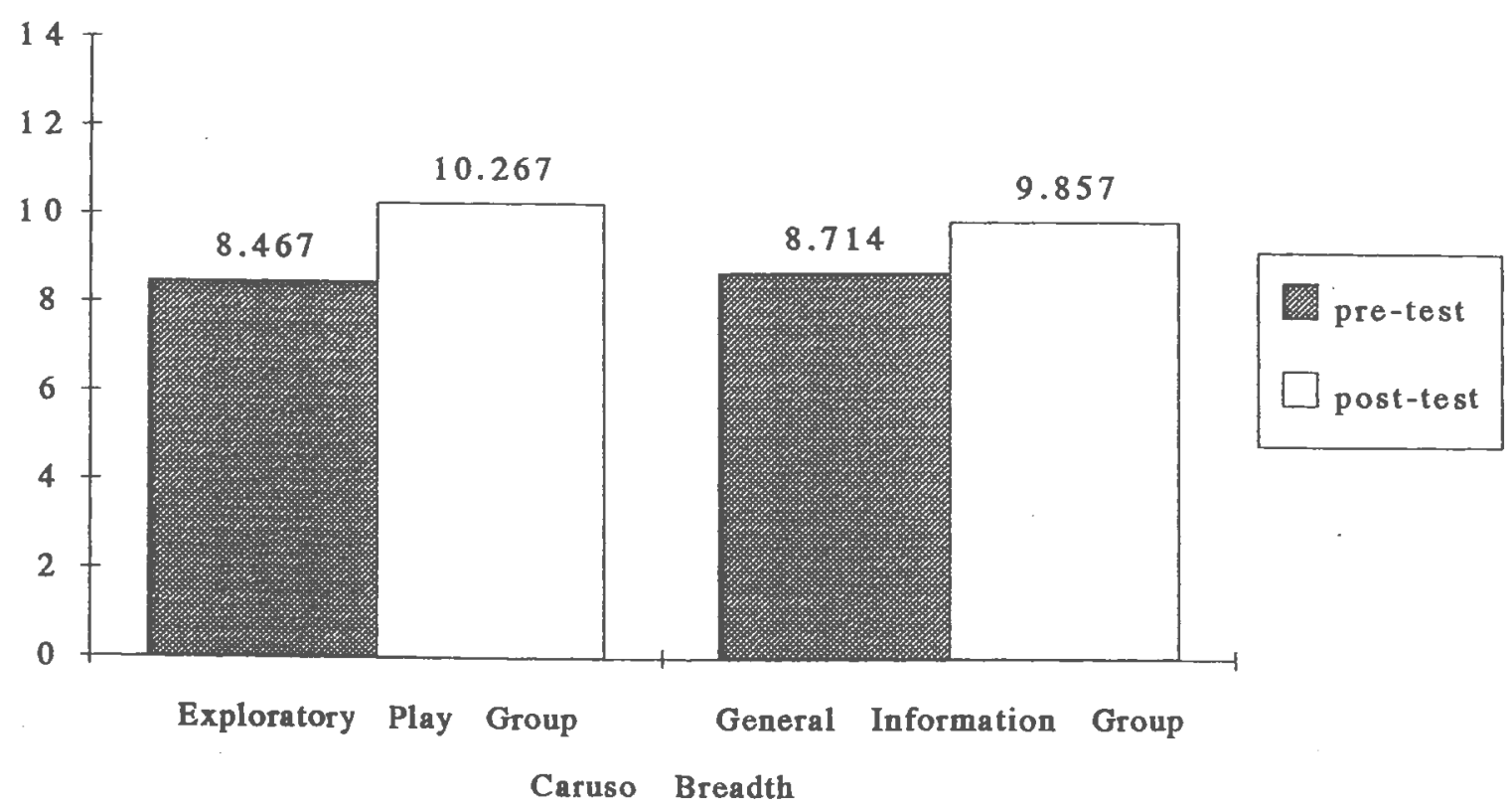


Figure 2.

Independent Play

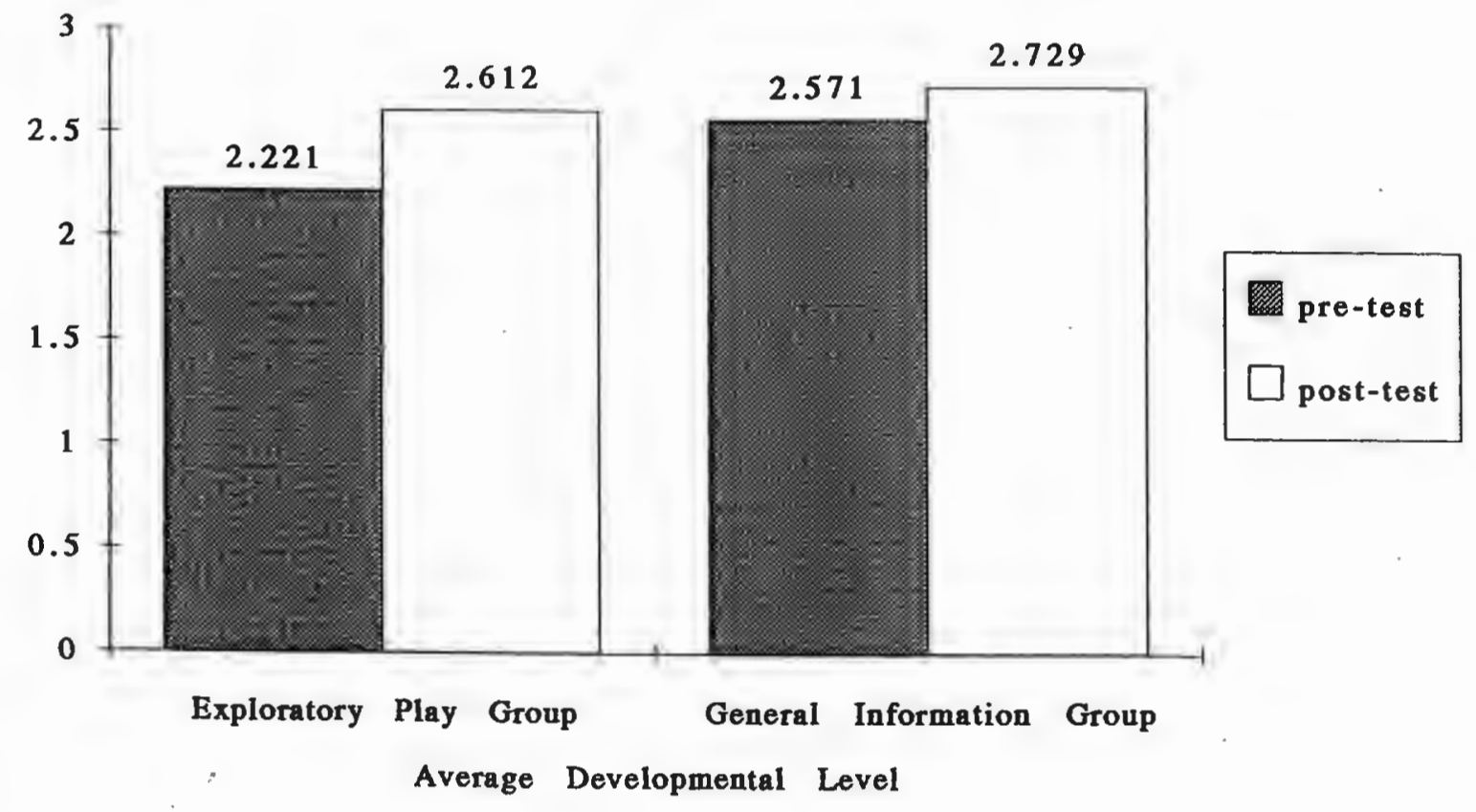

94 
Figure 3.

Independent Play

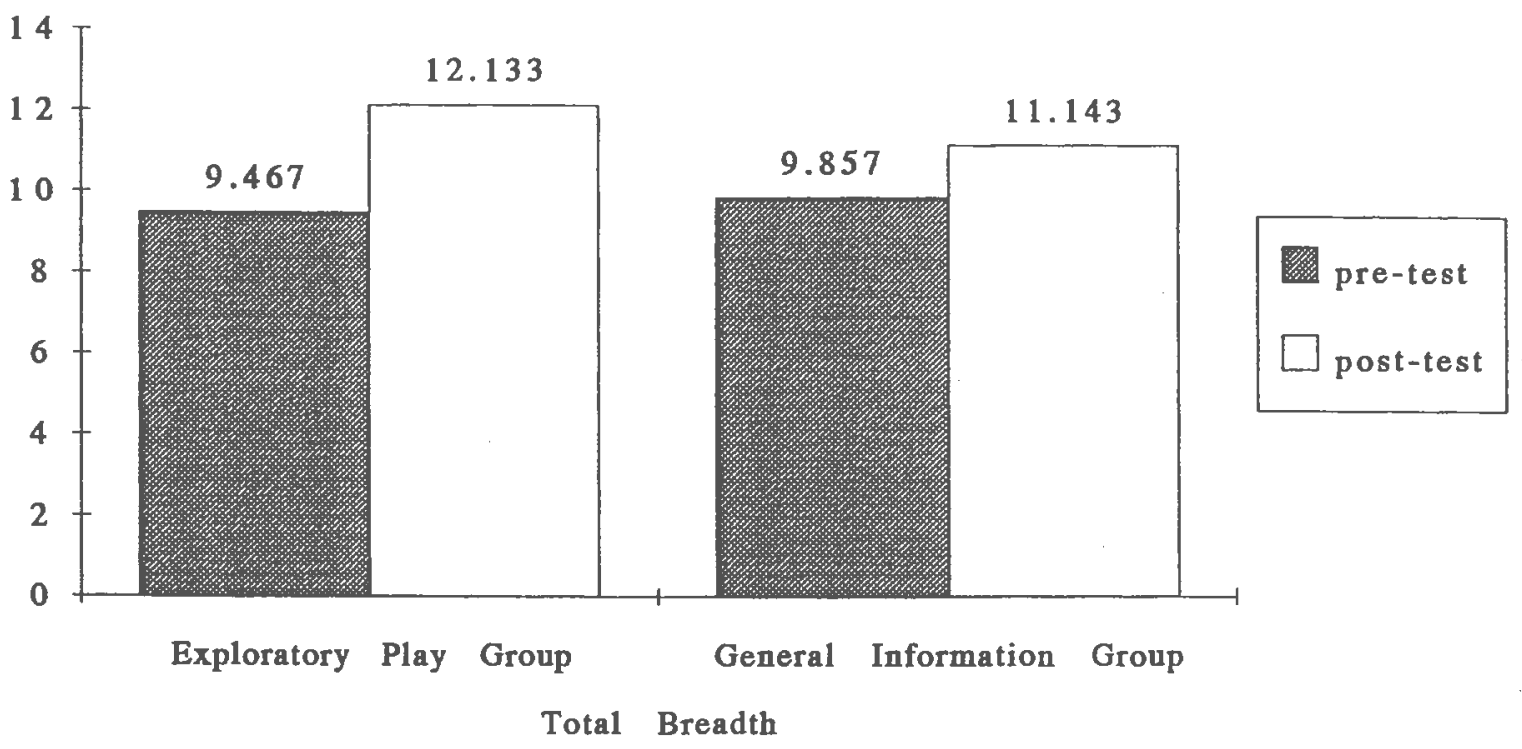


Figure 4.

Independent Play

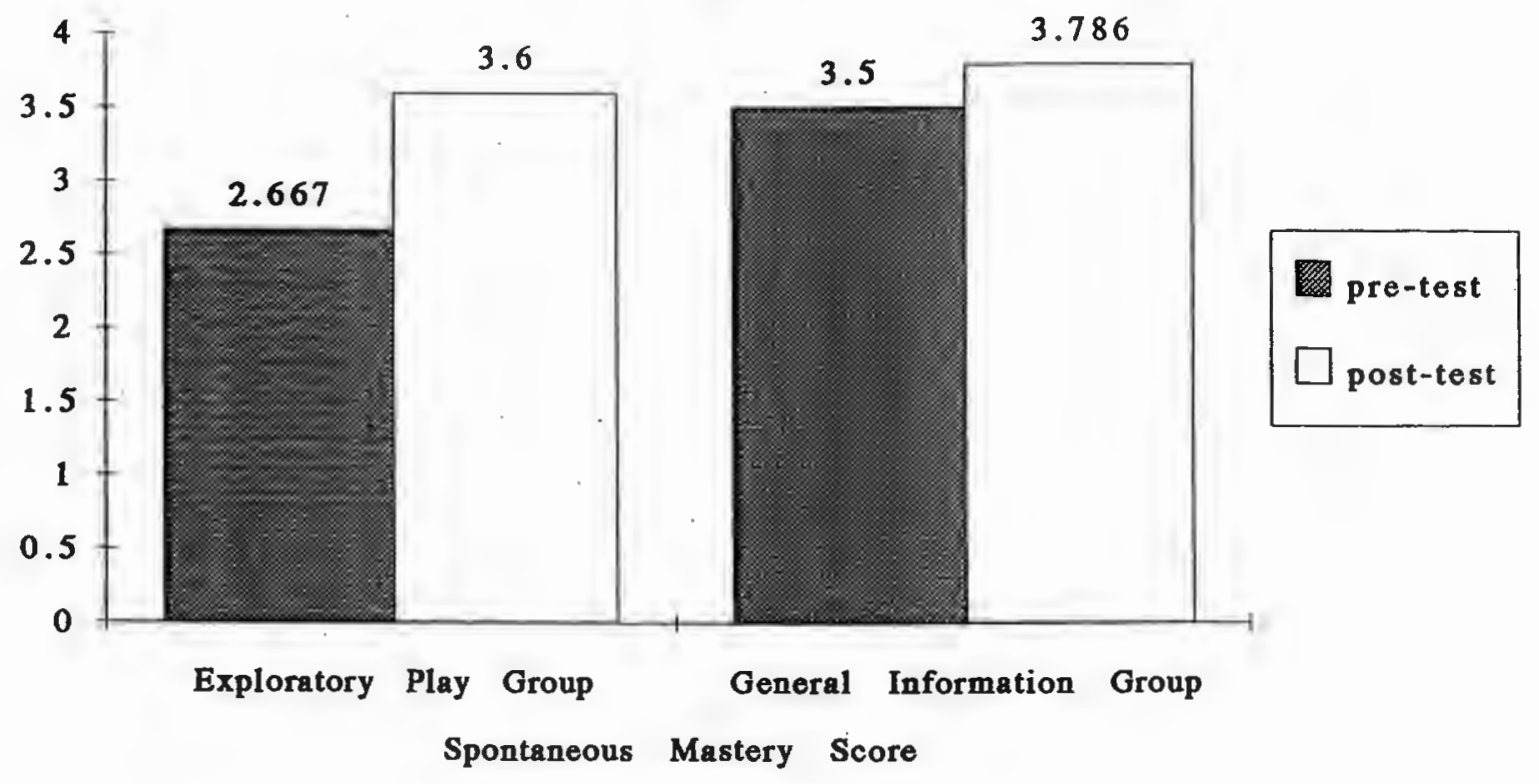


Figure 5.

Play with Caregiver

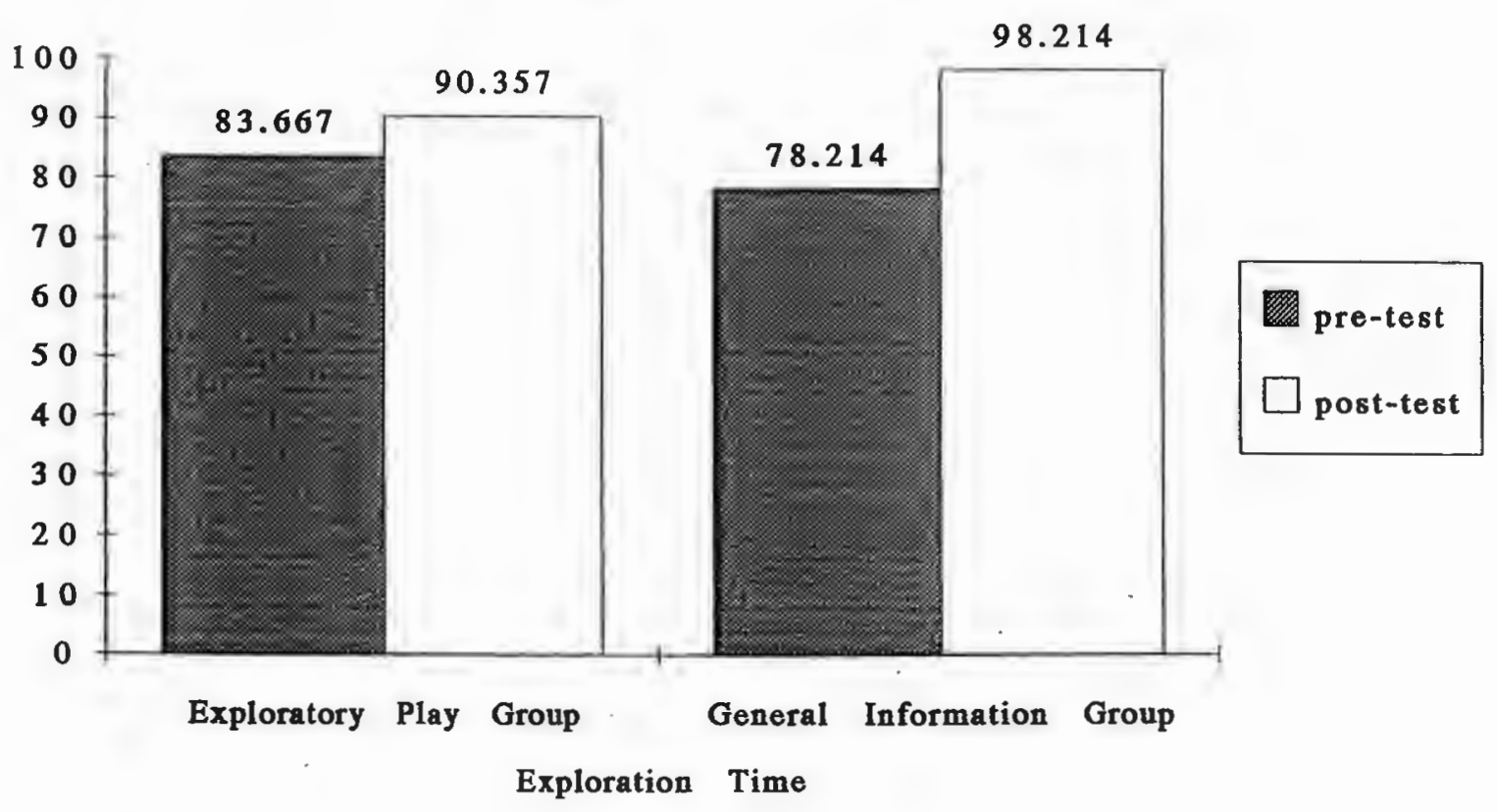


Figure 6 .

Play with Caregiver

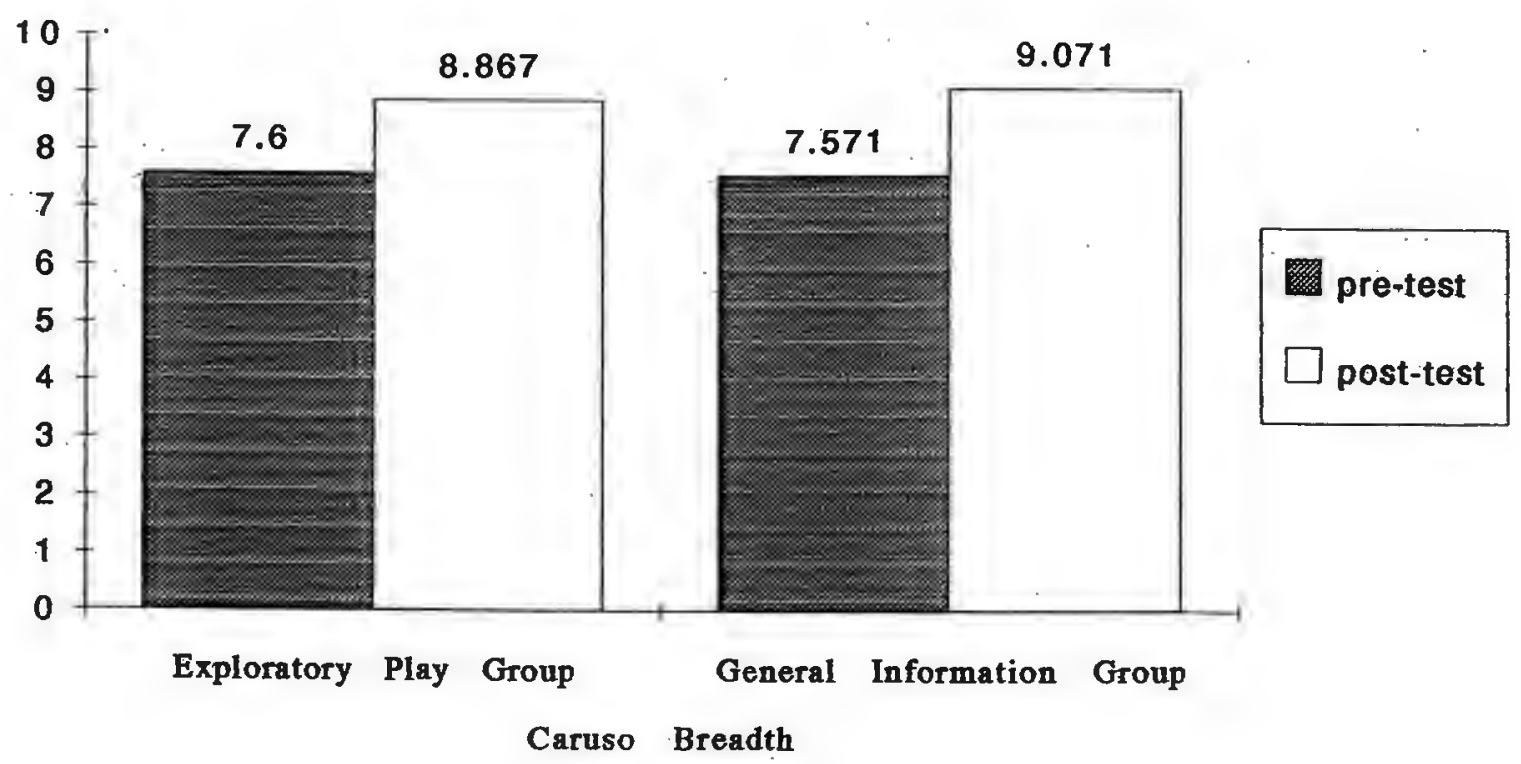


Figure 7.

\section{Play with Caregiver}

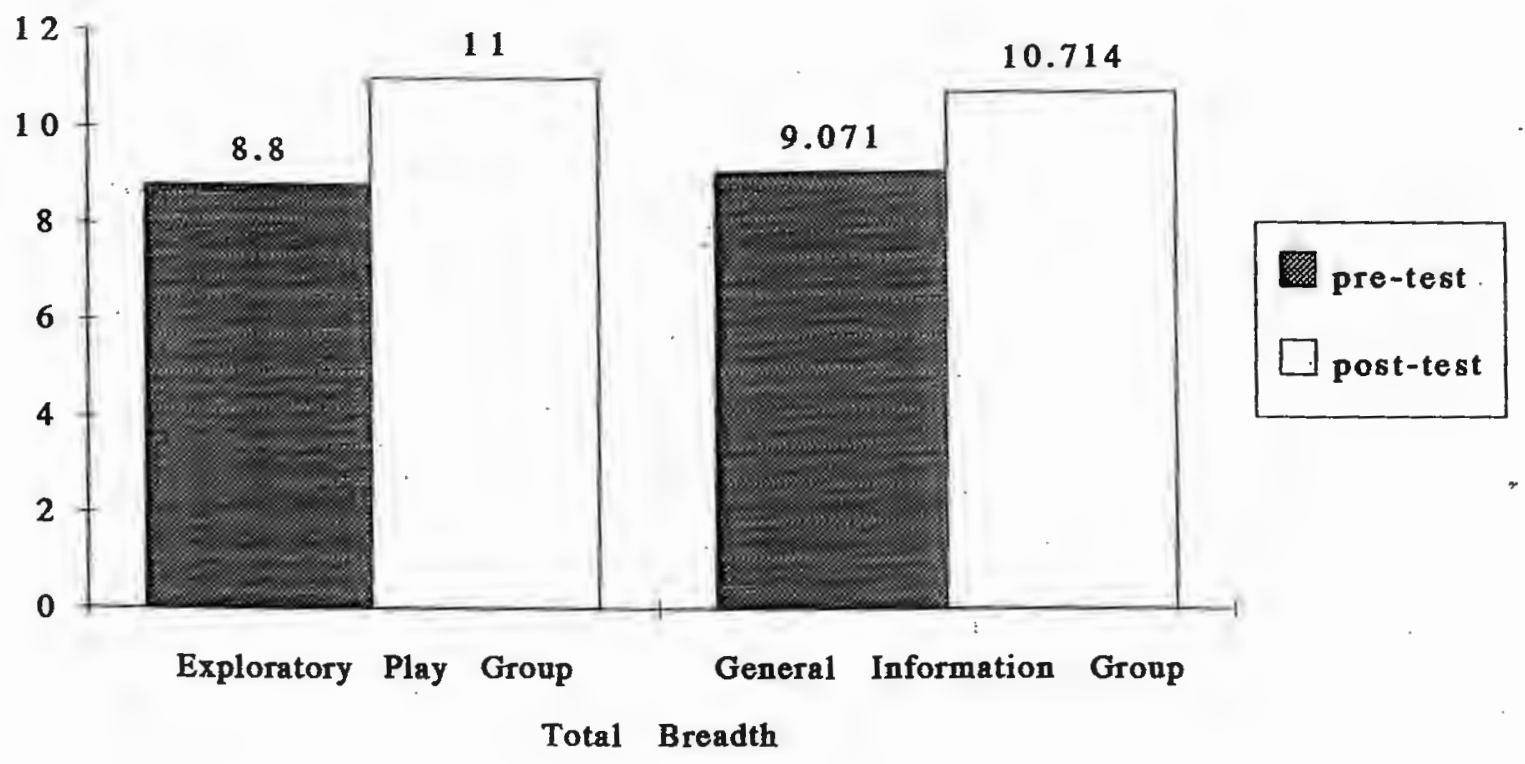


Anzalone, M. E. (1994). Mother-infant play at 9-months:

Developmental level, quality, and style. Unpublished doctoral dissertation, Boston University, Boston.

Barnard, K. E., Hammond, M., Booth, C., Bee, H., Mitchel, S., \& Spieker, S. (1989). Measurement and meaning of parent-child interaction. In F. Morrison, C., Lord, \& D. Keating (Eds.), Applied Developmental Psychology: Vol. 3. New York: Academic Press.

Belsky, J., Goode, M., \& Most, R. K. (1980). Maternal stimulation and infant exploratory competence: Cross-sectional, correlational and experimental analyses. Child Development, 51. 1163-1178.

Belsky, J., \& Most, R. K. (1981). From exploration to play: A crosssectional study of infant free play behavior. Developmental Psychology, 17, 630-639.

Bordens, K. S., \& Abbott, B. B. (1991). Research Design and Method: A Process Approach. Toronto: Mayfield.

Blasco, P. M., Hrncir, E. J., \& Blasco, P. A. (1990). The contribution of maternal involvement to mastery performance in infants with cerebral palsy. Journal of Early Intervention, 14, 161-174.

Bruner, J. S. (1973). Organization of early skilled action. Child Development, 44, 1-11.

Caruso, D. A. (1984, May). Individual differences in the variety of sensorimotor schemes children use to explore objects. Paper presented at the meeting of the Jean Piaget Society, Philadelphia, PA.

Caruso, D. A. (1985). Individual differences in two-year-olds' exploratory behavior: Relationships to problem-solving, home environmemt, and exploration and problem-solving at one year of age. Unpublished doctoral dissertation, Cornell University, New York. 
Caruso, D. A. (1986). Cognitive and motivational competence across the second year of life: Relationships to home environment and infant temperament. Paper presented at the meeting of the International Association for Infant Mental Health, Chicago.

Caruso, D. A. (1988). Play and learning in infancy: Research and Implications. Young Children, 1, 63-70.

Caruso, D. A. (1990). Exploratory play, task persistence and problem solving ability across the second year of life. Early Education and Development, 1. 354-370.

Caruso, D. A. (1993). Dimensions of quality in children's exploratory behavior: Relationships to problem-solving ability. Infant Behavior and Development, 16. 441-454.

Fiese, B. H. (1990). Playful relationships: A contextual analysis of mother-toddler interaction and symbolic play. Child Development, 61,1648-1656.

Hrncir, E. J., Speller, G. M., \& West, M. (1985). What are we testing? Developmental Psychology, 21, 226-232.

Hauser-Cram, P. (1996). Mastery motivation in toddlers with developmental disabilities. Child Development, 67, 236-248.

Hunt, J. (1965). Intrinsic motivation and its role in psychological development. Nebraska Symposium on Motivation, 13, 189-282.

Jennings, K., Harmon, R., Morgan, G., Gaiter, J., \& Yarrow, L. (1979). Exploratory play as an index of mastery motivation: Relationships to persistence, cognitive functioning and environmental measures. Developmental Psychology, 15, 386394.

Krakow, J. B., \& Kopp, C. B. (1983). The effects of developmental delays on sustained attention in young children. Child Development. 54, 1143-1155.

Krakow, J. B., \& Kopp, C. B. (1982). Sustained attention in young Down Syndrome children. Topics in Early Childhood Special Education. (July), 32-42. 
Mahoney, G. (1988). Enhancing the developmental competence of handicapped children. In K. Marfo (Ed.), Parent-child Interaction and Developmental Disabilities. New York: Praeger.

McCall, R. (1979). Infants. Cambridge: Harvard University Press.

Piaget, J., (1952). The Origins of Intelligence in Children. New York: International Universities Press.

Psychological Corporation (1993). Bayley Scales of Infant Development-Second Edition. New York: Author.

Rubin, K. H., Fein, G. G., \& Vandenburg, B. (1983). Play. In P. H. Mussen (Ed.), Handbook of Child Psychology Vol. 4. Socialization. Personality and Social Development. New York: John Wiley and Sons.

Tabachnick; B. G., \& Fidell, L. S. (1989). Using Multivariate Statistics. New York: Harper and Row, Publishers.

Vietze, P. M., McCarthy, M., McQuiston, S., MacTurk, R., \& Yarrow, L. J. (1983). Attention and exploratory behavior in children with Down's Syndrome. In T. Field \& A. Sostek (Eds.), Children Born At Risk: Physiological, Perceptual, and Cognitive Processes.

Weisler, A., \& McCall, R. B. (1976). Exploration and play: Resume and redirection. American Psychologist, 31, 492-508.

White, R. W. (1959). Motivation reconsidered: The concept of competence. Psychological Review, 66, 297-333.

Yarrow, L. J., MacTurk, R. H., Vietze, P. M., McCarthy, M. E., Klein, R. P., \& McQuiston, S. (1984). Developmental course of parental stimulation and its relation to mastery motivation during infancy. Developmental Psychology, 20, 492-503.

Yarrow, L., Rubenstein, J., \& Pederson, F. (1975). Infant and Environment. New York: Hemisphere.

Yarrow, L., Rubenstein, J., Pederson, F., \& Jankowski, J. (1972). Dimensions of early stimulation and their differential effects on infant development. Merrill-Palmer Ouarterly. 18. 205-218. 
Zigler, E. (1968). Developmental versus difference theories of mental retardation and the problem of motivation. American Journal of Mental Defiency, 73, 536-556. 